\title{
EVALUATION OF THERMOGRAPHIC PHOSPHOR TECHNOLOGY \\ FOR \\ AERODYNAMIC MODEL TESTING
}

\author{
M. R. Cates \\ K. W. Tobin \\ D. Barton Smith
}

Applied Technology Division

Prepared for AEDC/DOT

MIPR No. EY7483-89-0007

Date Prepared-August 1990

Prepared by the

Oak Ridge National Laboratory operated by

MARTIN MARIETTA ENERGY SYSTEMS

Oak Ridge, Tennessee 37831-7294

for the

U.S. DEPARTMENT OF ENERGY

under contract DE-AC05-84OR21400 


\section{CONTENTS}

LIST OF FIGURES $\ldots \ldots \ldots \ldots \ldots \ldots \ldots \ldots \ldots \ldots \ldots \ldots \ldots \ldots \ldots \ldots \ldots$

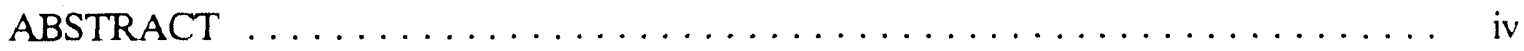

TEMPERATURE MEASUREMENTS USING TWO-COLOR. FHOSPHOR

THERMOGRAPHY $\ldots \ldots \ldots \ldots \ldots \ldots \ldots \ldots \ldots \ldots \ldots \ldots \ldots \ldots \ldots \ldots \ldots \ldots$

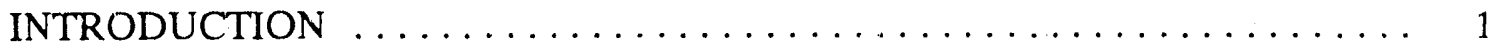

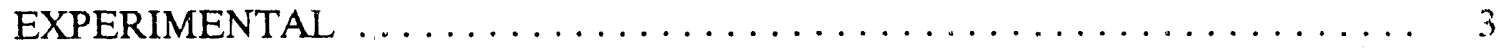

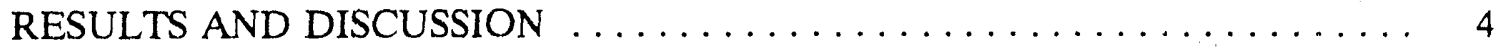

TWO-DIMENSIONAL SURFACE TEMPERATURE ESTIMATION USING

THERMOGRAPHIC PHOSPHORS $\ldots \ldots \ldots \ldots \ldots \ldots \ldots \ldots \ldots \ldots \ldots \ldots \ldots \ldots \ldots$

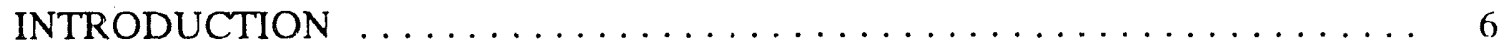

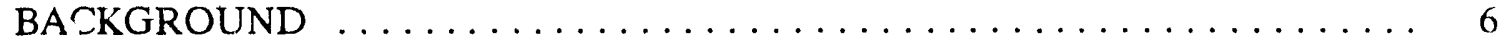

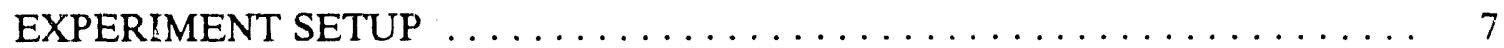

THEORY OF TWO-DIMENSIONAL IMAGING $\ldots \ldots \ldots \ldots \ldots \ldots \ldots$

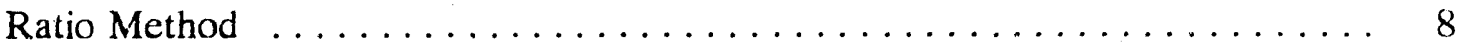

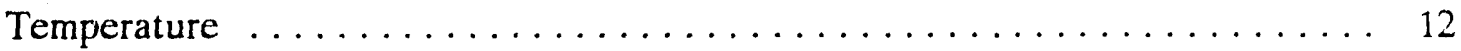

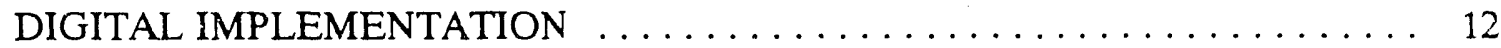

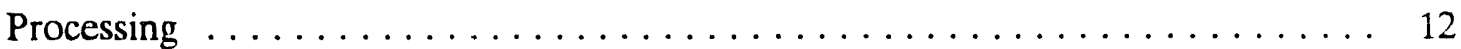

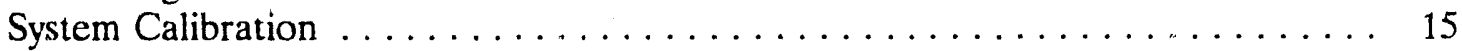

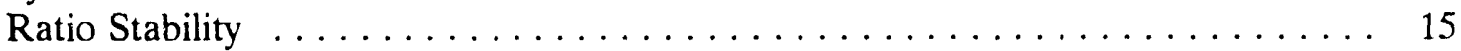

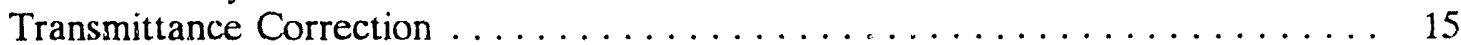

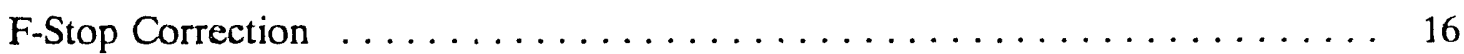

Calibration Curve ............................... 16

Calibrated Linear Model $\ldots \ldots \ldots \ldots \ldots \ldots \ldots \ldots \ldots$

RESULTS AND DISCUSSION $\ldots \ldots \ldots \ldots \ldots \ldots \ldots \ldots \ldots \ldots \ldots$

MATERIALS FOR HIGH TEMPERATURE MODELS $\ldots \ldots \ldots \ldots \ldots \ldots \ldots$.

MACHINABLE CERAMICS $\ldots \ldots \ldots \ldots \ldots \ldots \ldots \ldots \ldots \ldots \ldots \ldots \ldots$

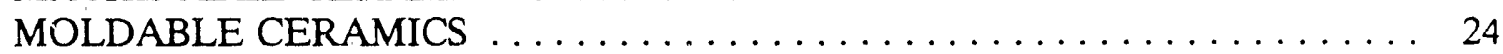

COATINGS ON SUBSTRUCTURES $\ldots \ldots \ldots \ldots \ldots \ldots \ldots \ldots \ldots \ldots \ldots$

CONCLUSIONS AND RECOMIMENDATIONS $\ldots \ldots \ldots \ldots \ldots \ldots \ldots \ldots$

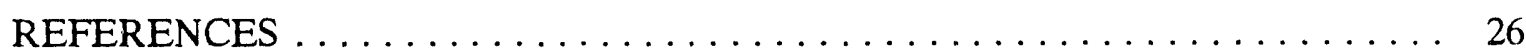




\section{LIST OF FIGURES}

1 Ratio of 629- and 611-nm-emission intensities as a function of $\mathrm{Y}_{2} \mathrm{O}_{3}: \mathrm{Eu}$

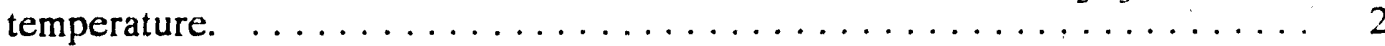

2 Ratio of 594- and 587-nm-emission intensities as a function of $\mathrm{YVO}_{4}: \mathrm{Eu}$

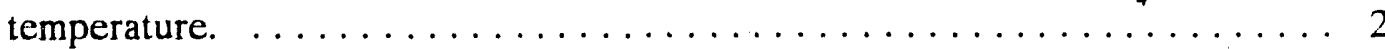

3 Ratio of 574- and 457-nm-emission intensities as a function of $\mathrm{YVO}_{4}: \mathrm{Dy}$ temperature.

4 Room-temperature fluorescence spectrum of a 2:1 mixture of $\mathrm{MgFGe}: \mathrm{Mn}$ and YAG:Tb. The phosphors were excited with $325-\mathrm{nm}$ radiation. . . . . . 3

5 Schematic diagram of apparatus used for emission-line-ratio measurements. . . 4

6 Emission signal observed at $622^{\circ} \mathrm{F}$ with 546 -nm filter. . . . . . . . . . 5

7 Ratio of 546- to 650-nm emission signal as a function of temperature for the emission lines of YAG:Tb at $544 \mathrm{~nm}$ and MgFGe:Mg at $657 \mathrm{~nm} . \ldots \ldots \ldots$

8 Experiment setup for demonstration of surface temperature calculation. . . . . 7

9 Emission spectrum of $\mathrm{Gd}_{2} \mathrm{O}_{2} \mathrm{~S}$ :Tb showing the two peaks selected for

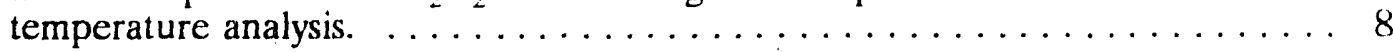

10 Coordinate system and nomenclature used for development of

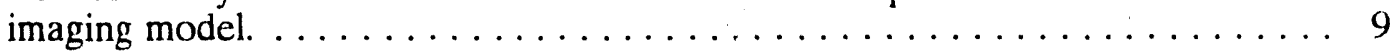

11 Schematic representation of the imaging process used to calculate and display the surface temperature map. $\ldots \ldots \ldots \ldots \ldots \ldots \ldots \ldots \ldots \ldots$

12 Detailed schematic of artifact-removal process. . . . . . . . . . . . . 14

13 Ratio stability demonstrated by the RCA video camera and image-processing system to a change in UV-excitation strength. $\ldots \ldots \ldots \ldots \ldots \ldots \ldots \ldots$

14 RCA-camera response to the two selected spectral lines. . . . . . . . . . 17

15 Calibration curve for selected phosphor showing linear region. . . . . . . 18

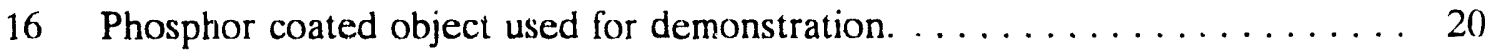

17 Temperature distribution across a curved surface using a simple

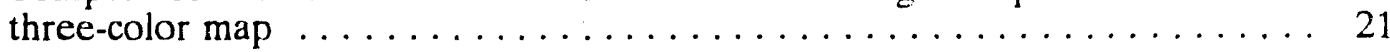

18 Temperature distribution across a curved surface using a continuous

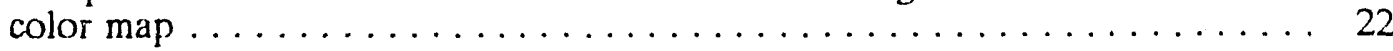




\begin{abstract}
The goal for this project was to perform technology evaluations applicable to the development of higher-precision, higher-temperature aerodynamic model testing at Arnold Engineering Development Center (AEDC) in Tullahmoa, Tennessee. With the advent of new programs for design of aerospace craft that fly at higher speeds and altitudes, requirements for detailed understanding of high-temperature materials become very important. Model testing is a natural and critical pait of the development of these new initiatives. The well-established thermographic phosphor techniques of the Applied Technology Division at Oak Ridge National Laboratory are highly desirable for diagnostic evaluation of materials and aerodynamic shapes as studied in model tests. Combining this state-of-the-art thermographic technique with modern, higher-temperature models will greatly improve the practicability of tests for the advanced aerospace vehicles and will provide higher precision diagnostic information for quantitative evaluation of these tests.

The wavelength ratio method of measuring surface temperatures of aerodynamic models was demonstrated in measurements made for this project. In particular, it was stown that the appropriate phosphors could be selected for the temperature range up to $\sim 700^{\circ} \mathrm{F}$ or higher and emission line ratios of sufficient sensitivity to measure temperature with $1 \%$ precision or better. Further, it was demonstrated that two-dimensional image-processing methods, using standard hardware, can be successfully applied to surface thermography of aerodynamic models for AEDC applications.
\end{abstract}




\section{TEMPERATURE MEASUREMENTS USING TWO-COLOR PHOSPHOR THERMOGRAPHY}

\section{INTRODUCTION}

The fluorescence spectrum of a rare-earth-doped phosphor is comprised of emission lines that are characteristic of the particular phosphor. The lines are produced by the radiative deexcitation of the dopant atoms in the host lattice, ${ }^{1}$ and it is well known that the line intensities and emission lifetimes are temperature-dependent properties. A phosphor that is utilized for its temperature-dependent properties is often referred to as a thermographic: phosphor.

If a thermographic phosphor is excited by a pulsed or continuous source of radiation (by a laser or arc lamp, for example), the ratio of the intensities of two emission lines is a unique function of temperature. By knowing the temperature dependence of this intensity ratio, it is possible to assess the temperature of the phosphor at an arbitrary temperature within the range for which the temperature dependence is known. Furthermore, when a surface is coated with a thin film of thermographic phosphor, the temperature of the surface can be determined by measuring the intensity ratio. Previous work ${ }^{2}$ done in collaboration with our group has demonstrated the feasibility of this temperature-measurement technique. Figures 1 through 3 show some of the results that were obtained with the phosphors $\mathrm{Y}_{2} \mathrm{O}_{3}:$ Eu, $\mathrm{YVO}_{4}: \mathrm{Eu}$, and $\mathrm{YVO}_{4}:$ Dy. The phosphors were excited by a pulsed source of ultraviolet radiation ( $\mathrm{N}_{2}$ laser with 337-nm emission and 7-ns-wide pulses), and for each phosphor, the intensities of two prominent emission lines were measured. The applicability of the ratio technique is clearly confirmed by the results; the ratios decrease with increasing temperature until the line intensities are no longer measurable by the analyzer.

The intensity-ratio technique can overcome many of the limitations imposed by a thermal-mapping heat-transfer technique. The technique does not require a uniform illumination of the surface under examination, and it requires only an illumination intensity sufficient to produce the emission lines. The relative intensities of the emission lines are insensitive to both the angle of illumination and the angle of detection, provided both lines are detected at the same location. The ratio technique is self-normalizing and does not require a background subtraction. The technique can be performed with a continuous excitation source similar to that used in the thermal mapping technique, or it can be performed with a pulsed excitation source. Furthermore, the technique is amenable to the color processing done in a red-green-blue (RGB) video system, thus allowing the capability to observe dynamic effects in real time.

In the present work, the surface temperature of a body inside a high-temperature oven was measured using the intensity-ratio technique. A mixture of two phosphors, YAG:Tb and $\mathrm{Mg}_{4} \mathrm{FGeO}_{6}: \mathrm{Mn}$, was used to obtain green (544-nm) and red (657-nm) emission lines $\sim$ ) to $600^{\circ} \mathrm{F}$. A fluorescence spectrum of this phosphor mixture is shown in Fig. 4. The characteristic green and red emissions from this phosphor are appropriate, for example, for observation with the RGB optics of color video systems. 


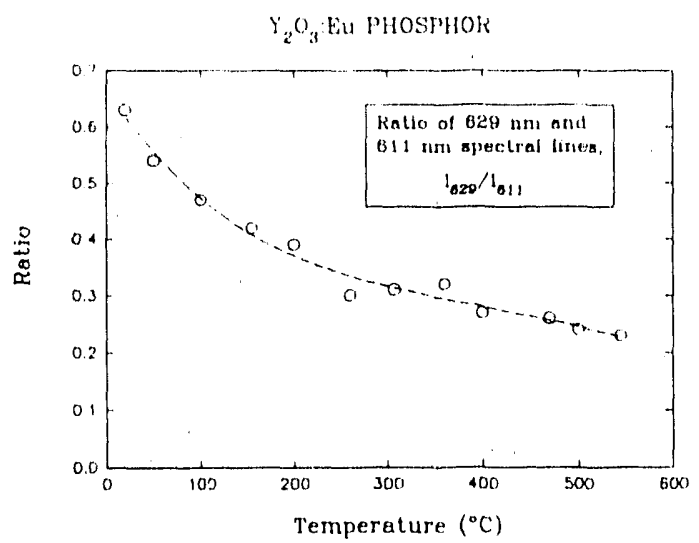

Fig. 1. Ratio of 629- and 611-nmemission intensities as a function of $\mathrm{Y}_{2} \mathrm{O}_{3}$ :Eu temperature.

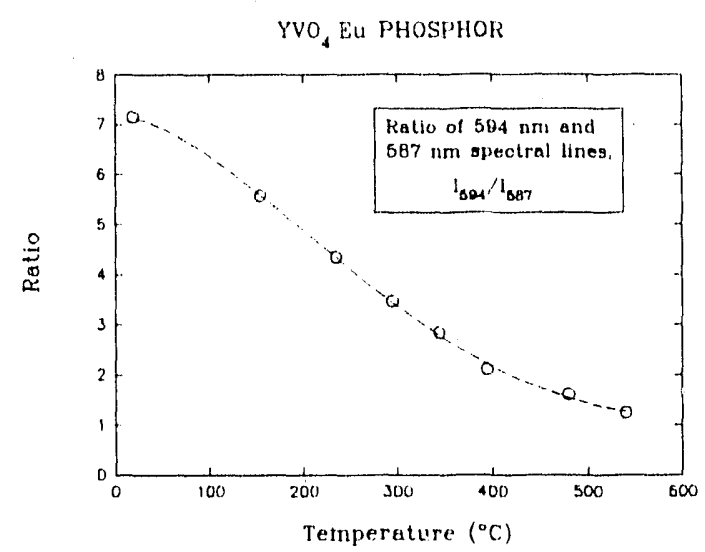

Fig. 2 Ratio of 594 and 587-nmemission intensities as a function of $\mathrm{YVO}_{4}$ :Eu temperature.

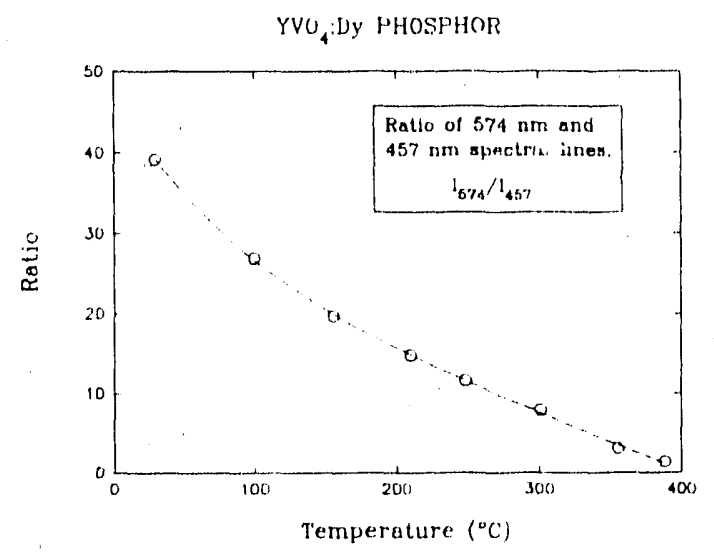

Fig. 3. Ratio of 574 and 457-nmemission intensities as a function of $\mathrm{YVO}_{4}$ :Dy temperature. 


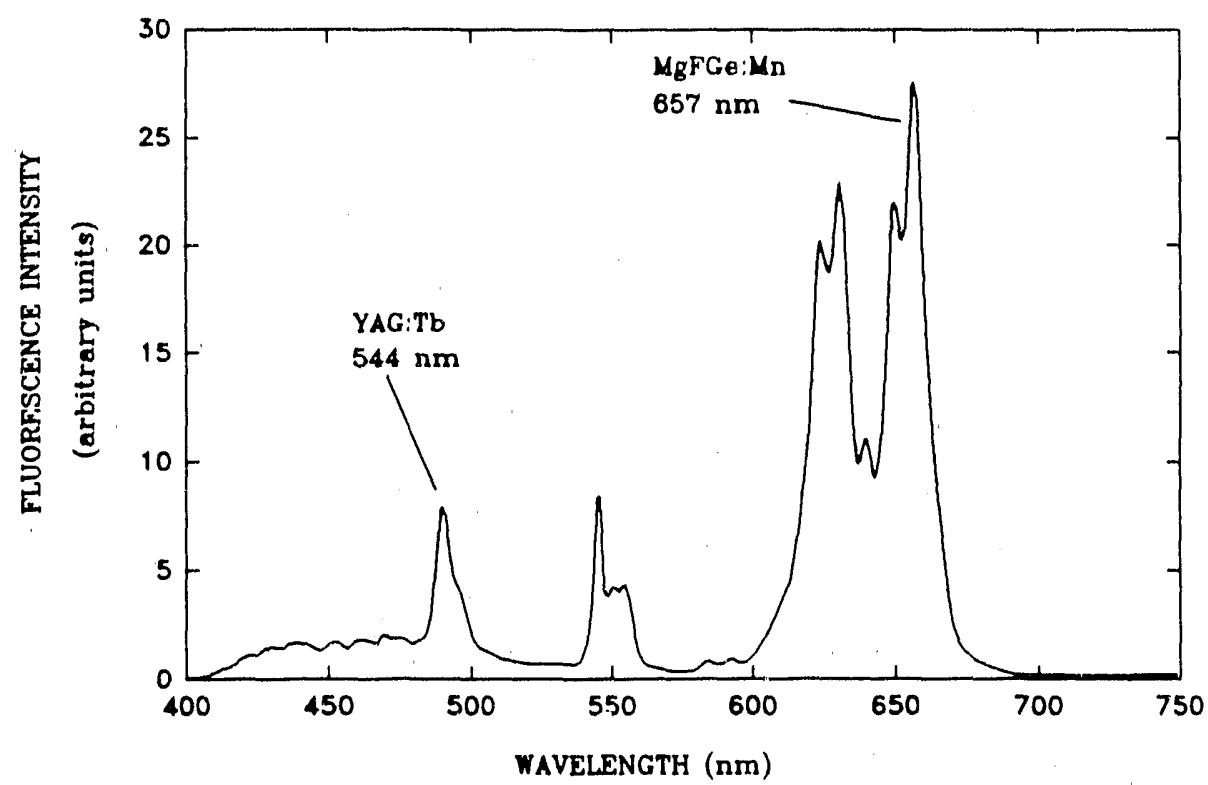

Fig. 4. Room-temperature fluorescence spectrum of a 2:1 mixture of MgFGe:Mn and YAG:Tb. The phosphors were excited with 325-nm radiation.

\section{EXPERIMENTAL}

Figure 5 shows the arrangement of the ratio-measurement apparatus. Equal volumes of powdered $\mathrm{YAG}: \mathrm{Tb}$ and $\mathrm{Mg}_{4} \mathrm{FGeO}_{6}: \mathrm{Mn}$ phosphors were mixed in propanol, and the resulting slurry was "painted" onto the surface of a nonfluorescing ceramic brick. The phosphor coating thus produced was $-0.5 \mathrm{~min}$ thick. The brick was then placed inside a hightemperature oven. During the course of the ratio measurements, the oven was operated in the 0 to $600^{\circ} \mathrm{F}$ range, and the temperature near the phosphors was measured with the use of a thermocouple probe. Because of the instability of the oven-temperature controller, the recorded temperatures had an uncertainty of $\pm 4^{\circ} \mathrm{F}$. This uncertainty was not critical to the evaluation of ratio technique because the trends and rough magnitudes of the effect were being studied.

An $\mathrm{HeCd}$ laser was used as the excitation source for the phosphor mixture. This laser provided a continuous wave (CW) beam of $325-\mathrm{nm}$ light having an output power of $-0.8 \mathrm{~mW}$. The beam was passed through a nort in the oven, and it illuminated the phosphors at $90^{\circ}$ incidence. The intensity of the laser beam on the phosphor coating was $-100 \mathrm{~mW} / \mathrm{cm}^{2}$. The $\mathrm{CW}$ output of the laser was chopped with an optical chopper as a means of preventing signal saturation in the photomultiplier tube used to detect the phosphor emission. The chopper was operated so that the CW beam was converted to a "pulsed" beam having 400 - $\mu \mathrm{s}$-long pulses occurring at a repetition rate of 74 pulses per second.

A portion of the phosphor emission was collected at one end of a 1-m-long glass-core optical fiber. This end of the fiber was positioned $\sim 5 \mathrm{~mm}$ from the phosphor surface, and the other end was coufled to the filter holder of the photomultiplier tube housing. To 
measure the intensities of the individual emission lines, two interference filters in the lilter holder were interchanged. One filter had a maximum transmission at $546 \mathrm{~nm}$, and the other had a maximum at $650 \mathrm{~nm}$. Both filters had a transmission bandwidth of $\pm 10 \mathrm{~nm}$. The output of the photomultiplier tube was amplified $100 \mathrm{X}$, and the amplified signal was recorded with a waveform-processing oscilloscope. The SYNC output of the optical chopper was used to trigger the oscilloscope, and the recorded emission-signal waveforms were formed from an average of 100 successive laser "pulses."

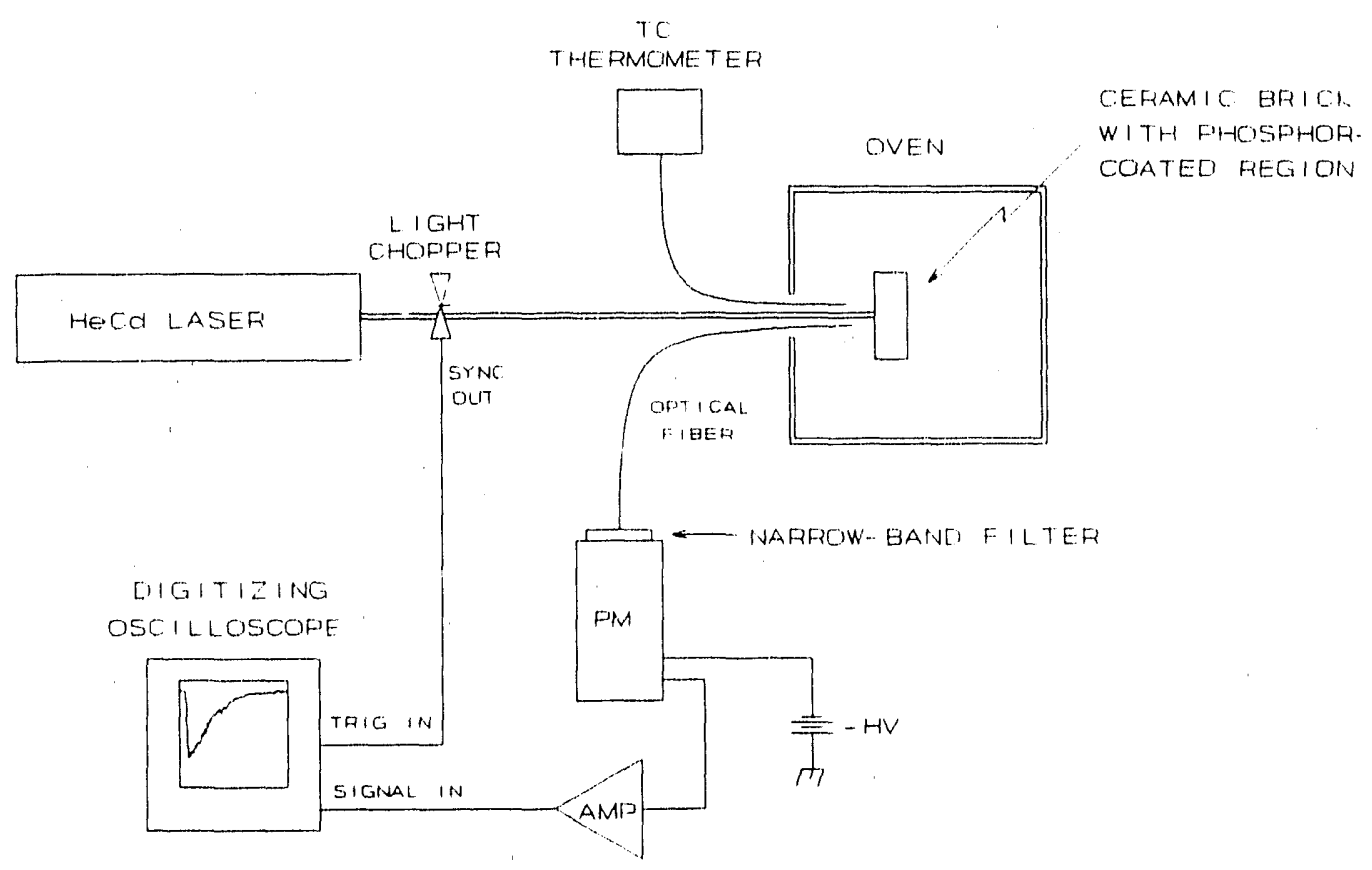

Fig. 5. Schematic diagram of apparatus used for emission-line-ratio measurements.

\section{RESULTS AND DISCUSSION}

A typical emission signal waveform as recorded by the digitizing oscilloscope is shown in Fig. 6. The onset of the signal occurred $\sim 1 \mathrm{~ms}$ after the oscilloscope was triggered, and the signal magnitude increased linearly for the next $0.4 \mathrm{~ms}$. This $0.4-\mathrm{ms}$ interval corresponds to the duration of the laser beam "pulse" produced by the optical chopper. When the chopper again blocked the beam, the signal decreased exponentially as the phosphorescence decayed.

At each oven temperature, the ratio of the $546-\mathrm{nm}$ signal to the $650-\mathrm{nm}$ signal was determined by integrating the signals that were observed during the chopper window (i.e., during the first $0.4 \mathrm{~ms}$ of the emission signal). This integration time was selected because it corresponded to the signal produced during illumination of the phosphors by the laser. Other convenient integration times could be used, provided the times are consistently applied to the data signals. Figure 7 shows the ratio measurements made in the temperature interval 68 to $622^{\circ} \mathrm{F}$. The intensity of both the 544 and $657-\mathrm{nm}$ lines increased with increasing temperature in this region, but the $657-\mathrm{nm}$-line intensity increased at a slower rate than the intensity of the 544-nm line. 


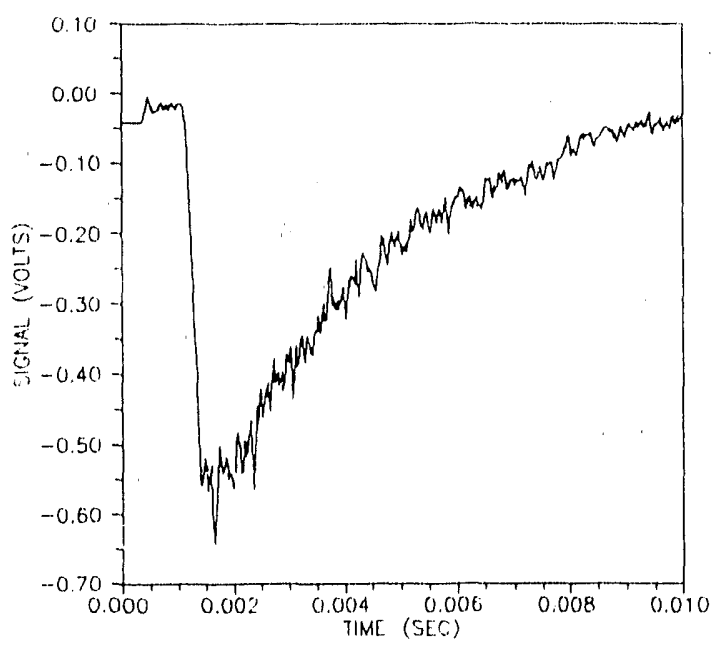

Fig. 6. Emission signal observed at $622^{\circ} \mathrm{F}$ with 546-nm filter.

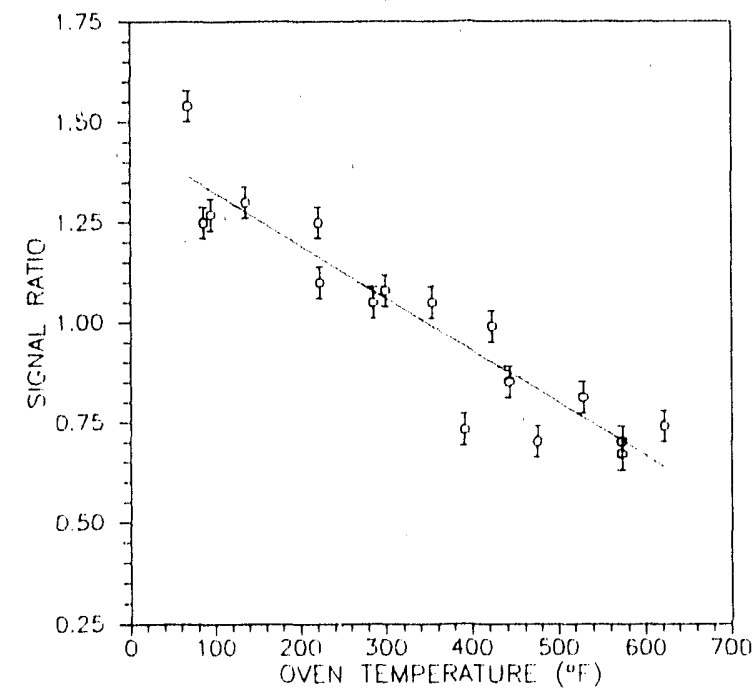

Fig. 7. Ratio of 546- to 650-nm emission signal as a function of temperature for the emission lines of YAG:Tb at $544 \mathrm{~nm}$ and MgFGe:Mg at 657-nm.

Figure $\%$ shows that the ratio decreased in a very nearly linear fashion in this region. The data are comprised of measurements made on four different days, which means that the phosphors were subjected to four heating and cooling cycles. The scatter of the ratio values about the least-squares fit is probably attributable to the instability in the laser output power (10\% root-mean-square noise in CW output power), which resulted in a considerable amount of puise-to-pulse variation in the emission signal. With the steady-state illumination provided in the Arnold Engineering Development Center (AEDC) test environment, the root-mean 
square noise is expected to be greatly reduced, thus allowing a more accurate calibration of the temperature dependence of the intensity ratio.

\section{TWO-DIMENSIONAL SURFACE TEMPERATURE ESTIMATION USING THERMOGRAPHIC PHOSPHORS}

\section{INTRODUCTION}

Once a candidate phosphor is selected to analyze the temperature regime of interest, a method must be developed to extract surface information from three-dimensional (3-D) objects such as those of wind tunnel models. The following method is an extension of the point ratio technique discussed in the previous section to two-dimensional (2-D) analysis. It has the advantage over other phosphor techniques in that determination of temperature will be independent of geometric distortions and illumination changes as the object undergoes stress. An advantage also exists over nonphosphor-based measurements, such as optical pyrometry, in that the narrow-band filtering of fluorescent emissions inherently discriminates against background noise arising from blackbody radiation. ${ }^{3}$ Also, the phosphor technique is not transmissivity and emissivity dependent.

The thermographic phosphor used for this experiment is gadolinium oxysulfide doped with terbium $\left(\mathrm{Gd}_{2} \mathrm{O}_{2} \mathrm{~S}: \mathrm{Tb}\right)$. The phosphor material is a ceramic consisting of a Group III metal oxide with a rare-earth dopant. The dopant ion introduces temperature-dependent electronicdecay transitions to the host molecule that are unique to the phosphor. The phosphor material is applied to the surface of interest and excited with a continuous-wave source of ultraviolet (UV) radiation to produce a visible spectrum of measurable fluorescence. A temperature-sensitive emission line and a temperature insensitive emission line are selected with narrow-band filters for the calculation. The amplitude of the spectral lines is a function of surface temperature and illumination/geometry conditions. By properly ratioing these data, the illumination and geometry affects can be mitigated and the surface temperature extracted.

\section{BACKGROUND}

Thermographic phosphor development and testing to date at the Oak Ridge National Laboratory (ORNL) includes high-temperature-furnace and atmospheric-combustor-chamber analysis to determine the degradation effects associated with different bonding methods. ${ }^{4}$ There have been stationary high-temperature spectrophotometer studies to determine temperature-sensitive spectral properties and dependencies, ${ }^{4,5}$ and rotating ambient temperature spin-rig tests to verify optical and electronic systems. The first temperature measurement on a component immersed in flame was conducted at the AEDC High Altitude Test Cell in Tullahoma, Tennessee." Phosphor was coated on a variable-area ejector located at the exhaust section of a turbine engine. Temperature data were collected while looking through a high-velocity afterburner flame. A rotating flame test was conducted in the atmospheric-combustor rig at Pratt \& Whitney in East Hartford, Connecticut. ${ }^{7}$ This test resulted in a series of temperature measurements made on a phosphor-coated rotating test vane irnmersed in a jet-flame spray. The first in-engine phosphor tests were completed 
recently. The first of these was a fixed-blade test which measured temperature on the firststage stator of a Pratt \& Whitney PW2037 turbine engine. ${ }^{8}$ The second test was performed on the first-stage turbine (rotating geometry) of a Pratt \& Whitney JT15D turbofan engine to evaluate the application of phosphor thermography to high-speed rotating in-engine surfaces. $^{8}$

\section{EXPERIMENT SETUP}

Figure 8 shows the experiment setup designed to demonstrate the ratio technique for surface-temperature measurement. An RCA low-light ISIT video camera was used to image fluorescent emission from a phosphor-coated specimen that was illuminated/excited with a dc UV lamp. The desired spectral component of the emission was obtained by placing a narrowband filter in the field of view. The video output (standard RS-170) of the RCA camera was then digitized to 8-bit precision using a Data Translation DT 2861 frame grabber and stored for processing. The data were processed using both the DT 2861 frame grabber and a DT 702032 -bit floating point array processor. The process was controlled by the host 80286 computer. The temperature-image data were then displayed on a standard 512 by 512 RGB color monitor. The target specimen was heated with a simple resistive heater that was controlled by a variac. Local surface points where monitored with thermocouples for calibration and verification.

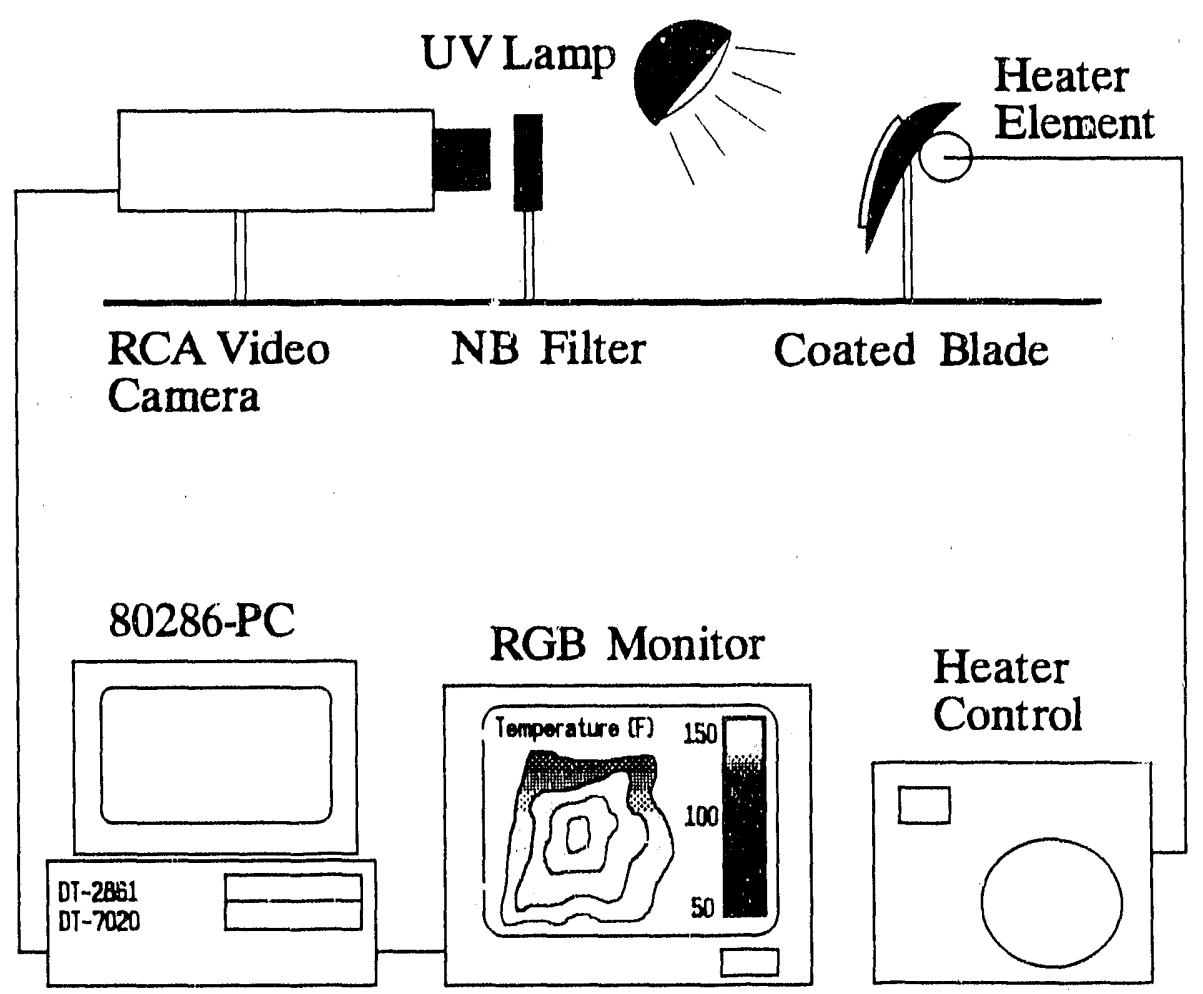

Fig. 8. Experiment setup for demonstration of surface temperaturc calculation. 
For the purpose of this experiment, a low-temperature phosphor was used. This allowed the setup to be easily adjusied and modified. As mentioned in the Introduction, the phosphor employed was $\mathrm{Gd}_{2} \mathrm{O}_{2} \mathrm{~S}: \mathrm{Tb}$ with an active temperature range (for the two spectral components analyzed) of 50 to $120^{\circ} \mathrm{F}$. The emission spectrum of the $\mathrm{Gd}_{2} \mathrm{O}_{2} \mathrm{~S}: \mathrm{Tb}$ phosphor is shown in Fig. 9. The spectral lines chosen for analysis were 415 and $490 \mathrm{~nm} .{ }^{9}$ High-temperature regimes are readily obtainable by choosing other spectral pairs or alternate phosphors, such as those discussed in the previous section, while applying the same algorithms.

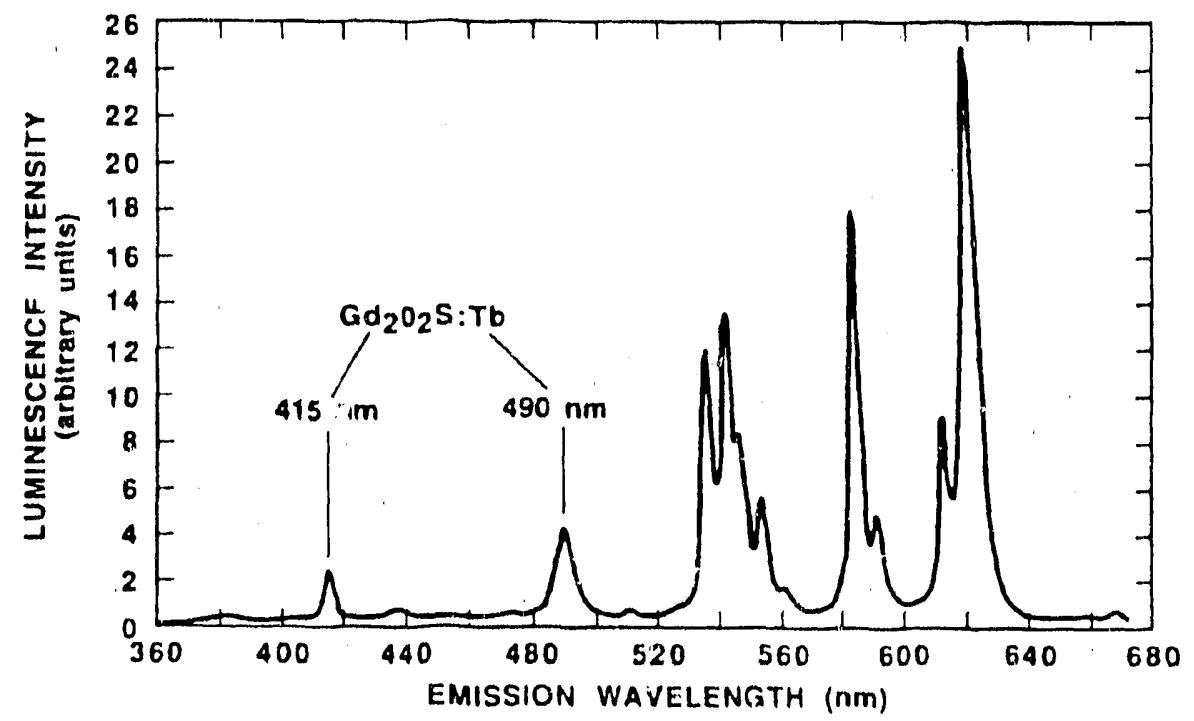

Fig. 9. Emission spectrum of $\mathrm{Gd}_{2} \mathrm{O}_{2} \mathrm{~S}$ : Tb showing the two peaks selected for temperature analysis.

\section{THEORY OF TWO-DIMENSIONAL IMAGING}

\section{Ratio Method}

The ability to remove geometric distorions and illumination variations from spectrally selected data will be shown by presenting an imaging model. This will demonstrate the theoretical limitations of the method and is the foundation for implementing the algorithms necessary to extract surface temperature. Figure 10 represents the imaging geometry and the associated nomenclature for the following development. The variables used in the analysis are defined as follows:

$8 \mathrm{O}_{\lambda}=$ fluorescent-emission radiance emanating fron. an infinitesimal surface patch on the object at wavelength, $\lambda$,

$\delta \mathrm{I}_{\lambda}=$ irradiance of emission photons onto the image plane, i.e., the imaged infinitesimal object patch at wavelength, $\lambda$,

$t_{\lambda}=$ narrow-band transmission fraction of the optics to wavelength, $\lambda$,

$\alpha=$ angle that an emission ray passing through the optics center makes with the optical axis, $z$, 
e = angle that the emission ray makes with the surface normal, $\hat{\mathrm{n}}$, associated with the object patch,

$(\theta, \phi)=$ polar and azimuthal angle associateu vith the surface normal, $\hat{f}$,

$f=$ fixed distance from the image plane to the lens,

$(\mathrm{x}, \mathrm{y})=$ coordinate system of the image plane, and

$\left(x^{\prime}, y^{\prime}, z\right)=$ coordinate system of the object surface.

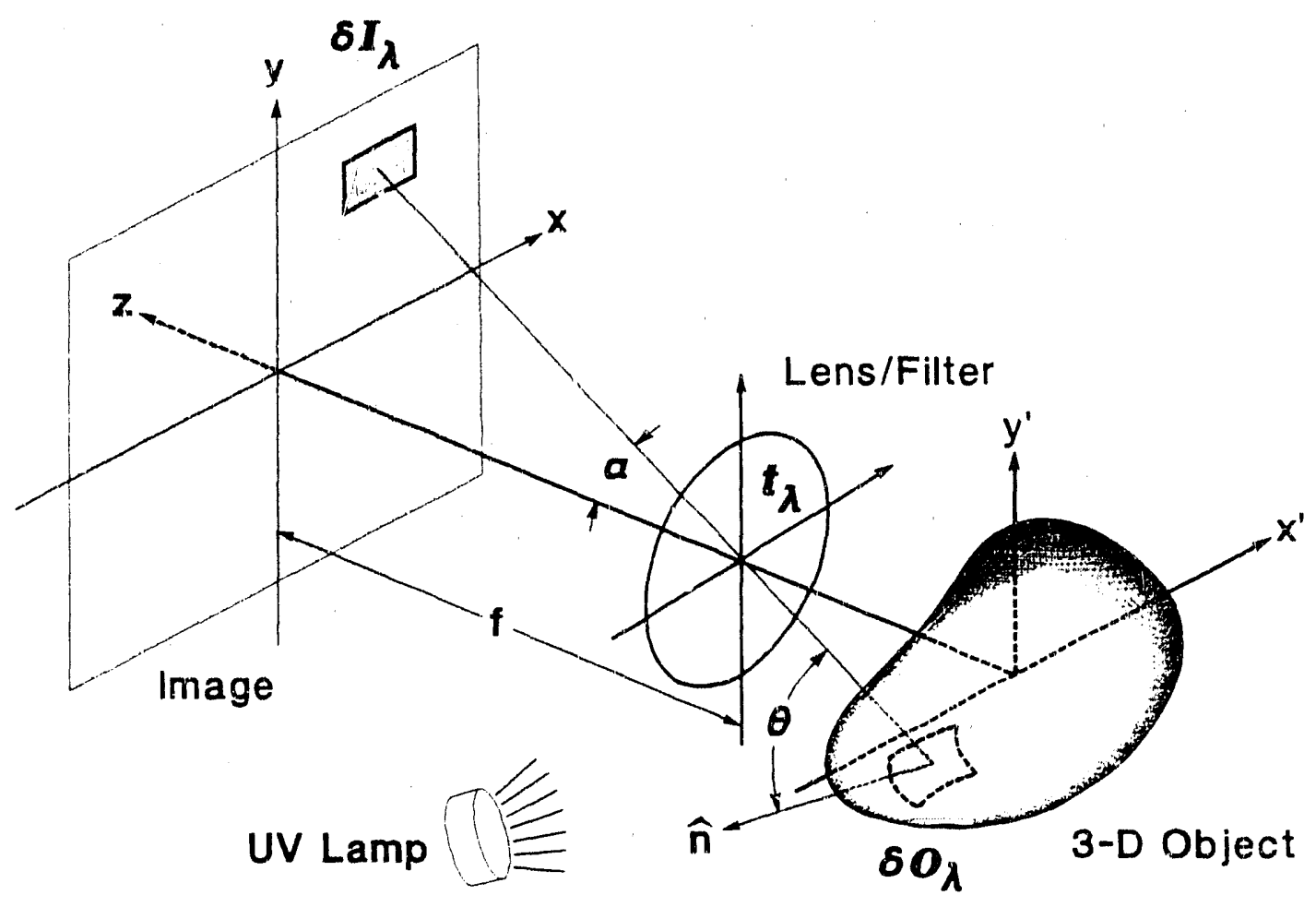

Fig. 10. Coordinate system and nomenclature used for development of irnaging model.

An expression for the distribution of object fluorescence at the image plane can be obtained by first describing the radiance from an infinitesimal object patch and how it interacts with the imaging plane (to create an infinitesimal image patch). The irradiance of the image patch arising from radiance, or fluorescence, of the object patch is expressed as ${ }^{10}$

$$
\delta I_{\lambda}(x, y)=t_{\lambda} \delta O_{\lambda}\left(x^{\prime}, y^{\prime}, z\right)\left(\frac{f}{z}\right)^{2} \frac{\cos \theta}{\cos \alpha}
$$


where the transformation from object coordinates $\left(x^{\prime}, y^{\prime}, z\right)$ to image plane coordinates $(x, y)$ is given by

$$
x=\frac{f}{z} x^{\prime}
$$

and

$$
y=\frac{f}{z} y^{\prime}
$$

The ass $\lrcorner$ mption will be made that the object surface depth coordinate, $z$, varies only slightly with respect to the distance from the image plane, i.e., the ratio $\mathrm{f} / \mathrm{z}$ will be treated as constant.

The dependence of $8 \mathrm{I}_{\lambda}(\mathrm{x}, \mathrm{y})$ on direction coordinates $(\theta, \phi)$ of the incident excitation and exitant emission is developed so that illumination and geometry responses of the system can be understood. Let the solid angle defined by the incoming and excitant radiations be defined by $\left(\theta_{i}, \phi_{i}\right)=\Omega_{i}$ and $\left(\theta_{e}, \phi_{e}\right)=\Omega_{e}$, respectively. The timperature-dependent object radiance, $8 \mathrm{O}_{\lambda}\left(\mathrm{x}^{\prime}, \mathrm{y}^{\prime}, \mathrm{z}, \mathrm{T} ; \Omega_{\mathrm{c}}\right)$ for emission at wavelength,, 2 , is then written as

$$
\delta O_{\lambda}\left(x^{\prime}, y^{\prime}, z, T ; \Omega_{e}\right)=\int_{\Omega_{1}} f_{\lambda}\left(x^{\prime}, y^{\prime}, z, T ; \Omega_{i}, \Omega_{e}\right) u\left(x^{\prime}, y^{\prime}, z ; \Omega_{i}\right) \cos \theta d \Omega_{i}
$$

where $\mathrm{u}\left(\mathrm{x}^{\prime}, \mathrm{y}^{\prime}, \mathrm{z} ; \boldsymbol{\Omega}_{\mathrm{i}}\right)$ is the direction-dependent distribution of the incident UV excitation at all incident angles, $\Omega_{\mathrm{i}}$. Note that $d \Omega_{\mathrm{i}}=\sin \theta_{\mathrm{i}} \mathrm{d} \theta_{\mathrm{i}} \mathrm{d} \phi_{\mathrm{i}}$ is the solid angle subtended by the object patch and the UV source. The term, $\cos \theta_{i}$, corrects the surface patch distribution for tilt of the surface normal, $\hat{\mathrm{n}}$, relative to the incoming excitation source. Finally, $\mathrm{f}_{\lambda}\left(\mathrm{x}^{\prime}, \mathrm{y}^{\prime}, \mathrm{z}, \mathrm{T} ; \Omega_{\mathrm{i}}, \Omega_{\mathrm{e}}\right)$ is the temperature-modulated distribution of emission photons at wavelength, $\lambda$. The function, $f_{\lambda}(\bullet)$, contains the thermal and spatial information associated with the phosphor-coated surface.

The phosphor-coated object will be approximated as a Lambertian emitter because an absorbed UV photon will be re-emitted as a visible photon (lower energy) with random direction. Therefore, the direction of an emitted photon (surface radiance) at wavelength, $\lambda$, due to the irradiant UV photon from the excitation source, is uncorrelated, and the dependency of $f_{\lambda}$ can be simplified as

$$
f_{\lambda}\left(x^{\prime}, y^{\prime}, z, T ; \Omega_{i}, Q_{e}\right) \rightarrow f_{\lambda}\left(x^{\prime}, y^{\prime}, z, T, Q_{e}\right)
$$

The temperature modulation of the fluorescence distribution will be modeled as a separable function of angular dependence and amplitude, i.e., the distribution is amplitude modulated as the energy of the incident UV photon is preferentially shared between electron and phonon excitation in the material lattice. ${ }^{11}$ The amplitude component of the separable function also contains the wavelength dependence of the fluorescence, 


$$
f_{\lambda}\left(x^{\prime}, y^{\prime}, z, T ; \Omega_{e}\right)=f\left(x^{\prime}, y^{\prime}, z ; \Omega_{e}\right) L_{\lambda}\left[T\left(x^{\prime}, y^{\prime}, z\right)\right]
$$

Equation (6) can be directly substituted into Eq. (4), and the coordinates $\left(x^{\prime}, y^{\prime}, z\right)$ transformed to (x,y) by applying Eqs. (2) and (3). This gives the infinitesimal object patch emission distribution as a function of image plane coordirates from which the image plane distribution is readily derived. The object patch distribution is now expressed by

$$
\begin{aligned}
\delta O_{\lambda}\left(x, y, T ; \Omega_{e}\right) & =\int_{\Omega_{i}} f\left(x, y ; \Omega_{e}\right) L_{\lambda}[T(x, y)] u\left(x, y ; \Omega_{i}\right) \cos \theta_{i} d \Omega_{i} \\
& =f\left(x, y ; \Omega_{e}\right) L_{\lambda}[T(x, y)] \int_{\Omega_{i}} u\left(x, y ; \Omega_{i}\right) \cos \theta_{i} d \Omega_{i} \\
& =f\left(x, y ; \Omega_{e}\right) L_{\lambda}[T(x, y)] U(x, y)
\end{aligned}
$$

where $U(x, y)$ is the geometry and amplitude function that defines the excitation source. It is a constant at each spatial point $(x, y)$ until the source is relocated or changes in intensity.

The above equation is combined with Eq. (1) to reveal the image patch distribution, $\delta I_{\lambda}$. arising from the object patch emission, $8 \mathrm{O}_{\lambda}$,

$$
\delta I_{\lambda}\left(x, y, T ; \Omega_{e}\right)=t_{\lambda} f\left(x, y ; \Omega_{e}\right) L_{\lambda}[T(x, y)] U(x, y)\left(\frac{f}{z}\right)^{2} \frac{\cos \theta}{\cos \alpha}
$$

The imaged intensity at any point on the image plane $(x, y)$ due to emission at object point $\left(x^{\prime}, y^{\prime}, z\right)$ is determined by integrating over all emission angles, $\Omega_{e}$, that are within the crillection field of the optics, i.e.,

$$
\begin{aligned}
I_{\lambda}(x, y, T) & =\int_{\Omega_{e}} \delta I_{\lambda}\left(x, y, T ; \Omega_{e}\right) \\
& =\int_{Q_{e}} t_{\lambda} f\left(x, y ; \Omega_{e}\right) L_{\lambda}[T(x, y)] U(x, y)\left(\frac{f}{z}\right)^{2} \frac{\cos \theta}{\cos \alpha} d \Omega_{e} \\
& =t_{\lambda} L_{\lambda}[T(x, y)] U(x, y) \int_{\Omega_{e}}^{e} f\left(x, y ; \Omega_{e}\right)\left(\frac{f}{z}\right)^{2} \frac{\cos \theta}{\cos \alpha} d \Omega_{e} \\
& =t_{\lambda} L_{\lambda}[T(x, y)] U(x, y) \stackrel{E}{E}(x, y),
\end{aligned}
$$

where $E(x, y)$ defines the object-emission geometry at each surface point $(x, y)$. Note that Eq. (9) represests the imaged distribution of emission photons as a separable function of excitation geometry and amplitude and emission geometry and modulated tenperaturedependent arnplitude. 


\section{Temperature}

The determination of surface temperature is accomplished by forming the ratio of two spectrally filtered images for known wavelengths $\left(\lambda_{1}, \lambda_{2}\right)$. The ratio will have a spatial and thermal dependence denoted by

$$
r(x, y, T)=\frac{I_{\lambda_{1}}(x, y, T)}{I_{\lambda_{2}}(x, y, T)}=\frac{t_{\lambda_{1}} L_{\lambda_{1}}[T(x, y)]}{t_{\lambda_{2}} L_{\lambda_{2}}[T(x, y)]}
$$

Note the geometry dependence on object illumination, $U^{\prime}(x, y)$, and fluorescent emission, $E(x, y)$, have canceled, leaving only a modulated amplitude response that is directly proportional to the surface temperature at all imaged points $(x, y)$. The surface temperature is extracted by empirical determination of a transform function, $\mathscr{F}\{\}$, that operates on the ratio given by Eq. (10), i.e,

$$
T(x, y)=\mathscr{F}\left\{\frac{t_{\lambda_{2}}}{t_{\lambda_{1}}} r(x, y, T)\right\}
$$

The response of the emission ratio for $\mathrm{Gd}_{2} \mathrm{O}_{2} \mathrm{~s}: \mathrm{Tb}$ at 415 - and $490-\mathrm{nm}$ has been demonstrated by Turley et al. $^{8}$ to be linear over the temperature range of $\sim 50$ to $120^{\circ} \mathrm{F}$. This linear response was verified for the video system described herein, and a thorough phosphor calibration was performed (discussed below). The transformation function that applies to the ratio image is defined for the linear system by

$$
T(x, y)=\mathscr{F}(r)=T_{h}-\left(T_{h}-T_{l}\right) \frac{\left(r-r_{l}\right)}{\left(r_{h}-r_{l}\right)}
$$

where $\left(T_{h}, T_{1}\right)$ and $\left(r_{h}, r_{1}\right)$ are the high and low limits of the phosphor temperature and ratio calibration, respectively.

\section{DIGITAL IMPLEMENTATION}

\section{Processing}

The RCA video camera generates a narrow-band-filtered analog signal (RS-170) which is sent to a DT-2861 8-bit frame-grabber/image processor as depicted in Fig. 11. Four images are gathered from the target object:

1. the numerator image corresponding to the $415-\mathrm{nm}$ narrow -band filter,

2. the numerator background taken while the illumination suurce is turned off,

3. the denominator image corresponding to the 490 -nm narrow-band filter, and

4. the denominator background image through the 490 -nm narrow-band filter. 


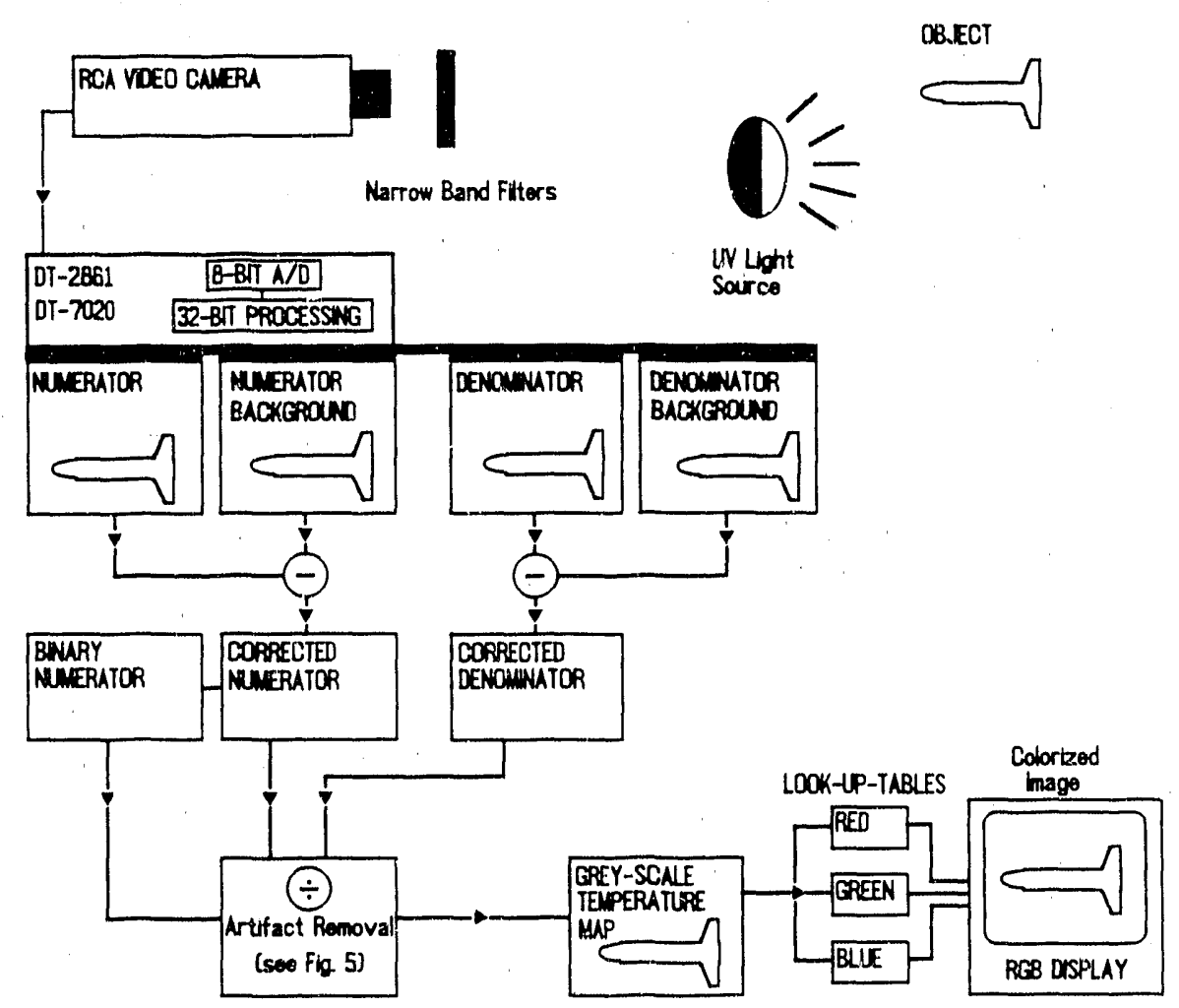

Fig. 11. Schematic representation of imaging process used to calculate and display surface temperature map.

Initially, the image backgrounds are subtracted to remove any dc-type offset associated with background illuminations of the target object.

Prior to processing the ratio of the images, a binary image map is generated from the numerator image for use in truncating uncoated (nonphosphor) ragions from the imaged scene. The binary image is used as a boolian mask in the process depicted in Fig. 12. The nonzero components of the mask are used to segment the imaged scene into image regions and regions containing zeros. The image regions are then processed to extract temperature information. The numerator image was chosen to generate the binary mask for this experiment because its emission amplitude was lower than that for the denominator. The numerator image, when set at a threshold, provides a conservative estimate of the object boundary.

Once the ratio of the numerator and denominator images has been obtained, the data are pushed through a linear vector process on the DT 7020 . The newly formed ratio, $r(\mathrm{i}, \mathrm{j})$, is handled by the array processor as a vector, $r=\left\{r_{k}, k=0,1, \ldots I J\right\}$, where $I$ and $J$ are the number of rows and columns, respectively, in the ratio image. The linear transformation to image grey-scale, g, as defined by Eq. (12), is implemented as

$$
\overrightarrow{\boldsymbol{g}}=c_{1}-c_{0} \gamma \vec{r},
$$


where

$$
c_{0}=\frac{g_{h}-g_{1}}{r_{h}-r_{l}}
$$

and

$$
c_{1}=g_{h}+c_{0} r_{l} \text {. }
$$
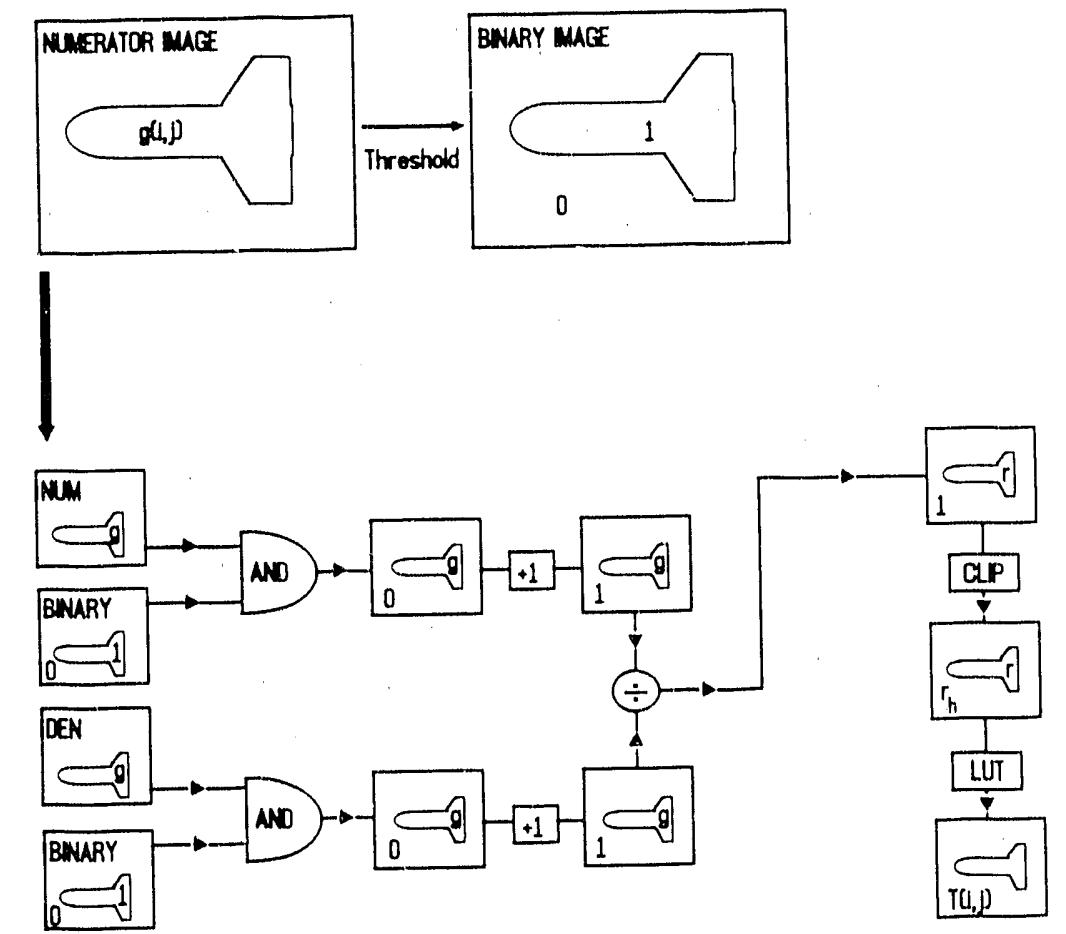

Fig. 12 Detailed schematic of artifact-removal process.

Note that $c_{0}, c_{1}$, and $\gamma$ are scaler quantities. The vector result for grey-scale, $g$, is easily transformed to temperature by a similar linear relationship,

$$
\pi[g(i, j)]=T_{h}-\left(T_{h}-T_{l}\right) \frac{g_{h}-g(i, j)}{g_{h}-g_{l}}
$$

where $\left(g_{h}, g_{l}\right)$ are the high and low limits of the grey-scale display, respectively. 


\section{System Calibration}

The calibration of the video system and thermographic phosphor material described here is not system specific, i.e., a similar calibration would be employed independent of the phosphor chosen or the video system used. It should be noted that the RCA video camero. used for this experiment was not optimal for phosphor thermography. The electronics associated with this imaging device were tailored toward human perception (low-light surveillance/monitoring) and not for calibrated machine vision applications. Regardless of these circumstances, the system performed adequately for the intended demonstration. The following topics summarize the procedure and data needed to calibrate the given video system, or any similar system, for 2-D surface temperature measurements.

Ratio Stability. To verify ratio processing of fluorescent emission data, a ratio stability test was performed. Figure 13 shows the ratio of the two phosphor spectral lines as the UVillumination source was varied in intensity. The UV intensity is signified by the indicated intensity of the denominator phosphur emission line (this emission line was more intense than the numerator line and therefore used as the reference). The mean and standard deviation of the : : ta over the range of values tested is $r=0.2071 \pm 0.0039$, while the slope of the linear itt is 0.00006 . The flat, linear response of the RCA camera shows that the system is acceptable for ratio processing.

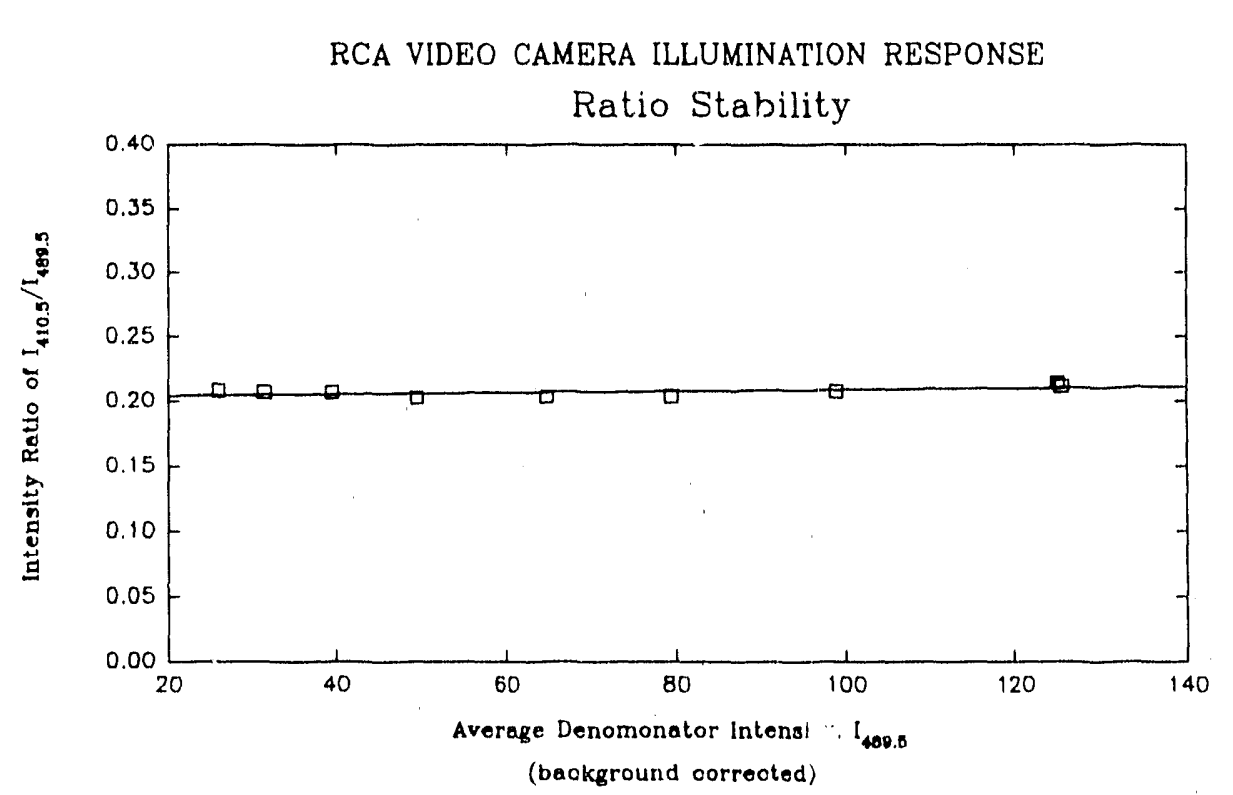

Fig. 13. Ratio stability demonstrated by the RCA video camera and image-processing system to a change in UV-excitation strength.

Transmittance Correction. According to the imaging theory presented earlier, the ratio data collected by the video system is corrected at each image point (i.e., each pixel) for transmittance values associated with the narrow-band filters. The need for this was expressed by Eq. (11) as 


$$
T(x, y)=\mathscr{F}\left\{\frac{t_{\lambda_{\text {den }}}}{t_{\lambda_{\text {max }}}} r(x, y, T)\right\},
$$

where the ratio, $t_{\lambda d e n} / t_{\lambda \text { num }}$, is determined from the peak amplitude transmittance specification of the narrow-band filters. For the current work, this ratio is 1.30. The peak-amplitudecorrection factor is used to normalize the ratio data associated with the phosphor so that application of different amplitude filters will result in approximately the same calibration.

F-Stop Correction. The two spectral lines associated with the selected phosphor have different emission amplitudes. This fact, coupled with the difference in transmittance efficiency of the narrow-band filters, results in having to use different aperture F-stops on the collection optics. The F-stop is the ratio of the lens focal length to its diameter. ${ }^{12}$ The lower the F-stop, the greater the exposure. The effect on the image data intensity has been corrected by applying a multiplier, $\gamma\left(F_{n u m}, F_{d e n}\right)$, to the ratio at each pixel. Once again, this normalizes the data such that the calibration of the selected phosphor is not necessarily system specific. The function, $\gamma$, is derived from measuring the video system response to the two phosphor spectral lines to empirically determine a log-linear slope metric as represented in Fig. 14.

The log-linear response of the system to a change in aperture F-stop is incorporated by the following relationship,

$$
\gamma\left(F_{n u m}, F_{d e n}\right)=e^{m\left(F_{d e n}-F_{n u m}\right)},
$$

where $\left(F_{n u m}, F_{d e n}\right)$ are the camera $F$-stops used for the numerator and denominator images, respectively. The calibrated image ratio, $r$, at point $(x, y)$ is now expressed as

$$
r(x, y)=\frac{I_{\text {num }}(x, y)}{I_{\text {den }}(x, y)} \frac{t_{\lambda_{\text {den }}}}{t_{\lambda_{\text {num }}}} \gamma\left(F_{\text {num }}, F_{d e n}\right)
$$

Calibration Curve. Using the transmittance and gamma correction factors described previously, the $\mathrm{Gd}_{2} \mathrm{O}_{2} \mathrm{~S}$ : Tb phosphor was calibrated for the video system over a temperature range of 70 to $160^{\circ} \mathrm{F}$. A phosphor-coated aluminum surface was configured with a variac controlled resistive heater element on the back side, and a small thermocouple on the front side. The front surface was imaged with the video sy:sem. A small region of interest was defined surrounding the thermocouple from which to acquire data. This individual pixels located in this region were averaged together at a given temperature and used as a calibration point. Table 1 lists the collected data, and Fig. 15 shows the calibration curve resulting rom the analysis. 


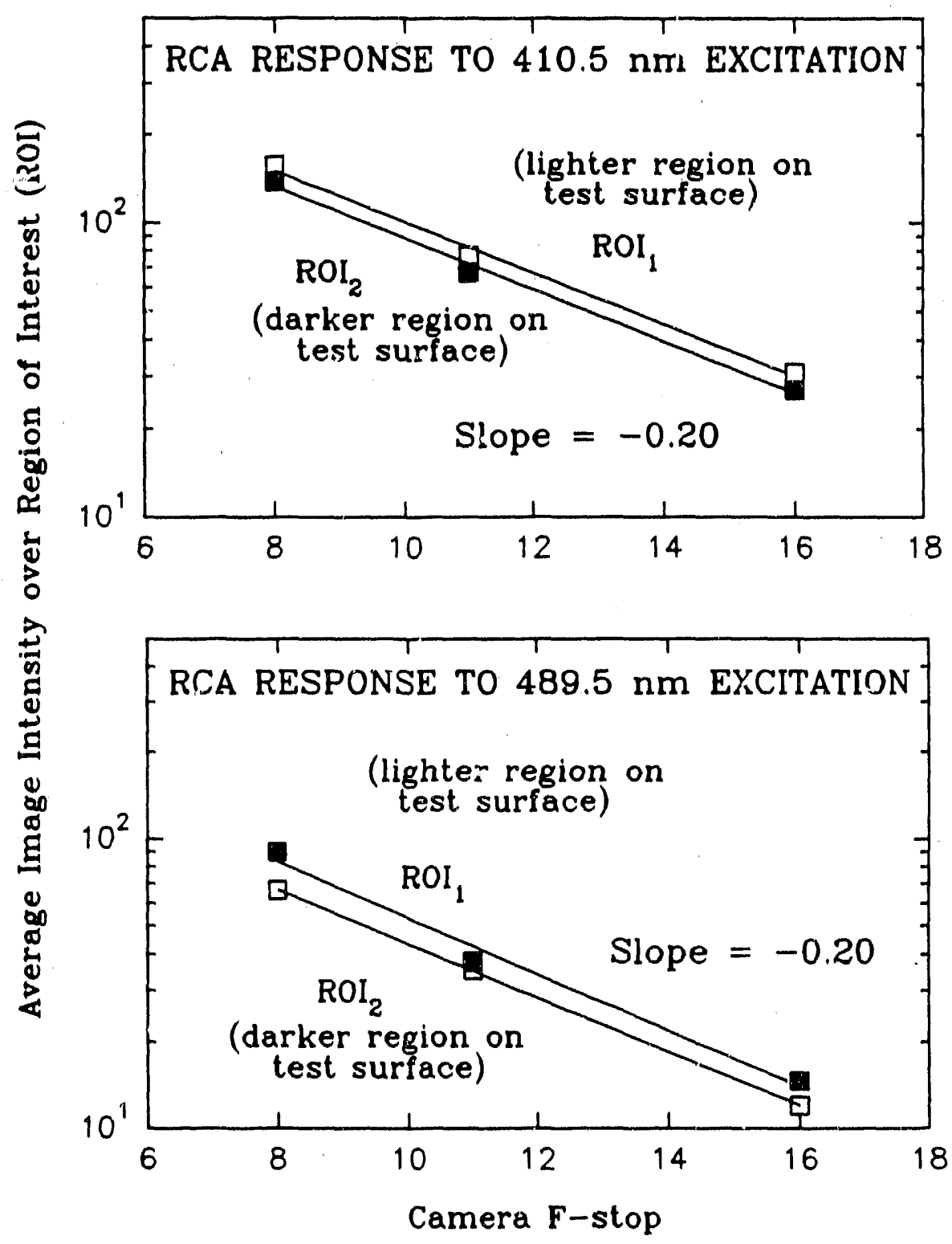

Fig. 14. RCA-camera response to the two selected spectral lines. These data were used to calibrate the $\gamma$-correction factor.

Calibrated Linear Model. Using the calibration data from the $\mathrm{Gd}_{2} \mathrm{O}_{2} \mathrm{~S}$ :Tb phosphor, the final form of the mapping model used for this work is given by

$$
T(r)= \begin{cases}F\left[r_{l}\right], & r<r_{l} \\ F[r], & r_{l} \leq r \leq r_{h} \\ F\left[r_{h}\right], & r>r_{h}\end{cases}
$$


Table 1. Calibration data collected with the RCA video cam and image-processing system.

\begin{tabular}{cccc}
\hline $\begin{array}{c}\text { Numerator image } \\
(410.5 \mathrm{~nm})\end{array}$ & $\begin{array}{c}\text { Denominator image } \\
(489.5 \mathrm{~nm})\end{array}$ & $\begin{array}{c}\text { Surface TC } \\
\left({ }^{\circ} \mathrm{F}\right)\end{array}$ & Corrected ratio \\
\hline 35.3 & 73.1 & 74.2 & 0.2186 \\
30.5 & 70.5 & 88.2 & 0.1955 \\
24.7 & 65.0 & 105 & 0.1717 \\
21.1 & 63.3 & 120 & 0.1506 \\
18.9 & 60.3 & 130 & 0.1413 \\
16.2 & 53.2 & 156 & 0.1317 \\
\hline
\end{tabular}

CALIBRATION CURVE FOR $\mathrm{Gd}_{2} \mathrm{O}_{2} \mathrm{~S}$ : Tb (using RCA video camera)

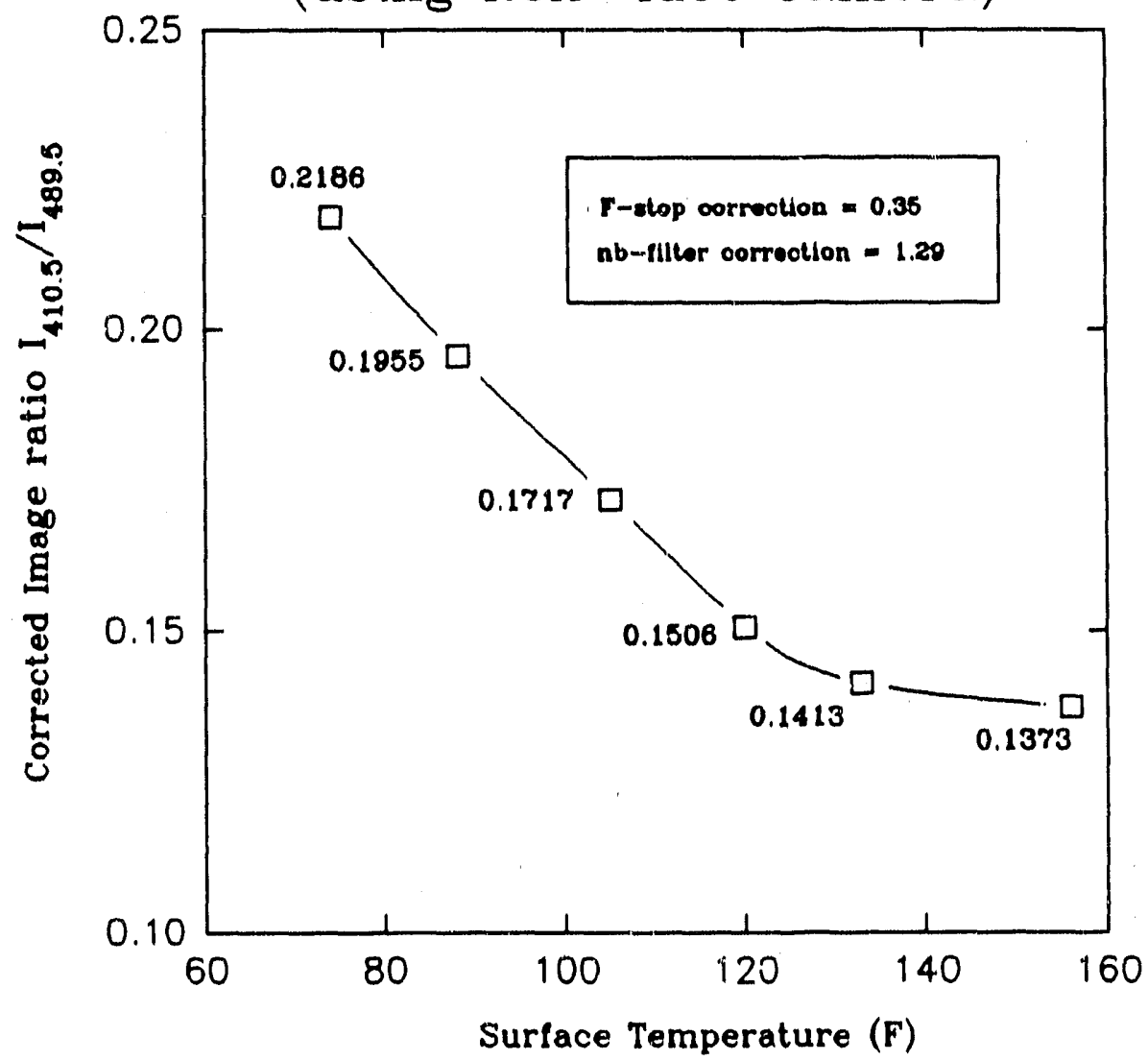

Fig. 15. Calibration curve for selerted phosphor showing linear region. 
where

$$
F(r)=T_{h}-\left(T_{h}-T_{l}\right)\left(\frac{r-r_{l}}{r_{h}-r_{l}}\right)
$$

It should be noted that the ratio argument in Eq. (18) is the corrected value, i.e.,

$$
r \rightarrow r \cdot \frac{t_{\lambda_{d m}}}{t_{\lambda_{m}}} \gamma\left(F_{\text {num }}, F_{d e n}\right)
$$

The parameters chosen for this experiment and used to generate the following results are shown in Table 2.

\begin{tabular}{|c|c|c|}
\hline & Calibration data & Correction factors \\
\hline $\begin{array}{l}\mathrm{T}_{\mathrm{h}}=130^{\circ} \mathrm{F} \\
\mathrm{T}_{1}=50^{\circ} \mathrm{F}\end{array}$ & $\begin{array}{l}\text { [Temperature transform, } \\
\text { Eqs. (14) \& (18)] }\end{array}$ & $\begin{array}{l}\gamma\left(F_{\text {num }}, F_{\text {den }}\right)=0.35 \\
t_{\lambda d \text { den }} / t_{\lambda \text { num }}=1.29\end{array}$ \\
\hline $\begin{array}{l}G_{h}=255 \\
G_{1}=0\end{array}$ & $\begin{array}{l}\text { [Grey-scale transform, } \\
\text { Eq. }(13)]^{a}\end{array}$ & $\begin{array}{ll}\mathfrak{t}_{\text {inum }}=0.43 \text { at } 410.5 \mathrm{~nm} & \text { (narrow-band } \\
\mathrm{t}_{\lambda \text { den }}=0.56 \text { at } 490.5 \mathrm{~nm} & \text { peak transmission } \\
& \text { values })\end{array}$ \\
\hline $\begin{array}{l}\mathrm{r}_{\mathrm{b}}=0.2532 \\
\mathrm{r}_{1}=0.1352\end{array}$ & & \\
\hline
\end{tabular}

Table 2. Calibration and correction parameters for video system display.

${ }^{a}$ Values for $G_{h}$ and $G_{1}$ were chosen to maximize the dynamic range of the 8-bit intensity

\section{RESULTS AND DISCUSSION}

The theory and algorithms described previously were used to implement a simple experiment of the calibrated $\mathrm{Gd}_{2} \mathrm{O}_{2} \mathrm{~S}$ : Tb ratio system. A phosphor coated aluminum tube was masked off in an arbitrary pattern to simulate object boundaries on a 3-D surface as shown in Fig. 16. A resistive heater was placed behind the imaged surface, and heated to develop a temperature gradient across the surface. The object was then illuminated with a mercury-vapor UV lamp, and data were collected through the video optics for both the 410.5 and the 489.5-nm narrow-band filters.

Figures 17 and 18 show the colorized grey-scale temperature distribution across the object surface for two separate false-color maps. Figure 17 is colorized with a simple bar scheme using a red, green, and blue set of color bars adjustable in width, spacing, and position. Figure 18 was colorized with a more complex color spectrum that is also adjustable in width 
and position. The dynamic color definition makes it possible to interactively vary the extent and width of the temperature range of interest.

The increase in object surface temperature is apparent from the two figures, but note the grainy texture and lack of fine temperature resolution. Based on the calibration data shown in Fig. 15, the resolution limit appears as though it should approach $\pm 2^{\circ} \mathrm{F}$. The inage noise associated with the initial emission data is intensified by the ratio process but can be mitigated substantially by properly filtering

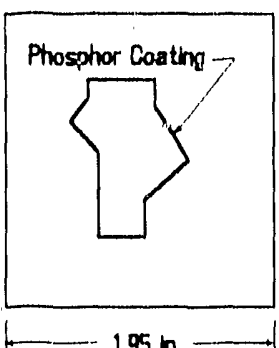

$-195 \mathrm{~h}$

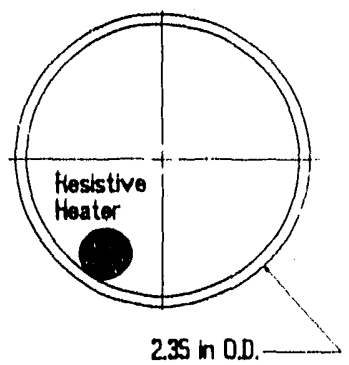

Fig. 16. Phosphor-coated object used for demonstration. the preratio data. A simple low-pass filter applied to the individual numerator and denominator images prior to ratioing will improve the display resolution accordingly. This type of filtering is readily available with other imageprocessing hardware and software packages but was not available for this demonstration system. The noise that vevelops in the ratio process is represented by the following:

$$
\frac{I_{n u m}(x, y) \pm \sigma_{n u m}}{I_{d e n}(x, y) \pm \sigma_{d e n}}=r(x, y) \pm \sigma_{r},
$$

where the ratio noise, $c_{r}$ is expressed as ${ }^{13}$

$$
\sigma_{r}=\frac{I_{\text {num }}(x, y)}{I_{d e n}(x, y)} \sqrt{\left(\frac{\sigma_{\text {ium }}}{I_{\text {num }}(x, y)}\right)^{2}+\left(\frac{\sigma_{d e n}}{I_{d e n}(x, y)}\right)^{2}} .
$$

Assuming that an average standard error, $\sigma_{\text {image }}=1 / 2\left(\sigma_{\text {num }}+\sigma_{\text {den }}\right)$, and pixel intensity, $I_{\text {image }}$, for both numerator and denominator images, Eq. (21) can be expressed in a simple form as

$$
\sigma_{r}-\sqrt{2} \frac{\sigma_{\text {image }}}{I_{\text {image }}}
$$

Based on this result, the ratio image can be substantially improved by either increasing the intensity level of the gathered data (reducing $\sigma_{r}$ ) or by filtering the imaged surface to reduce the number of spurious low-intensity pixels (also reducing $\sigma_{r}$ ).

It should be noted from the calibration data shown in Fig. 15, over the temperature range of 74.2 to $120^{\circ} \mathrm{F}$, the linear portion of the curve predicts good temperature resolution. The linear curve fit to. this region is given by 


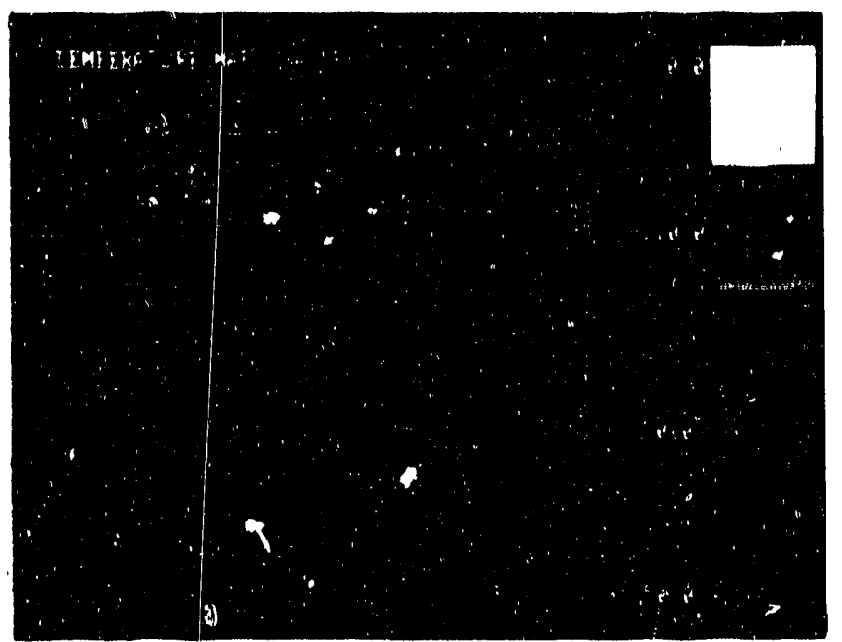

(a)

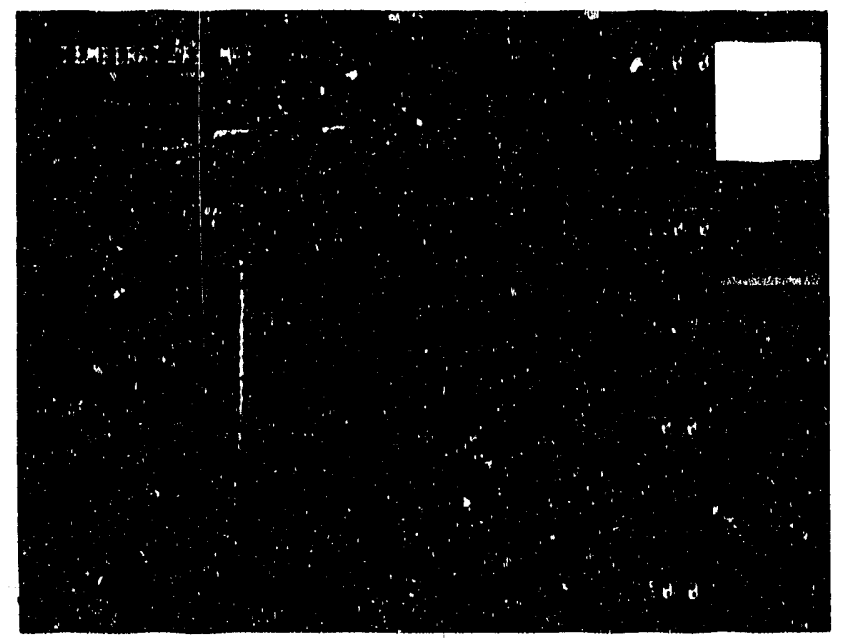

(b)

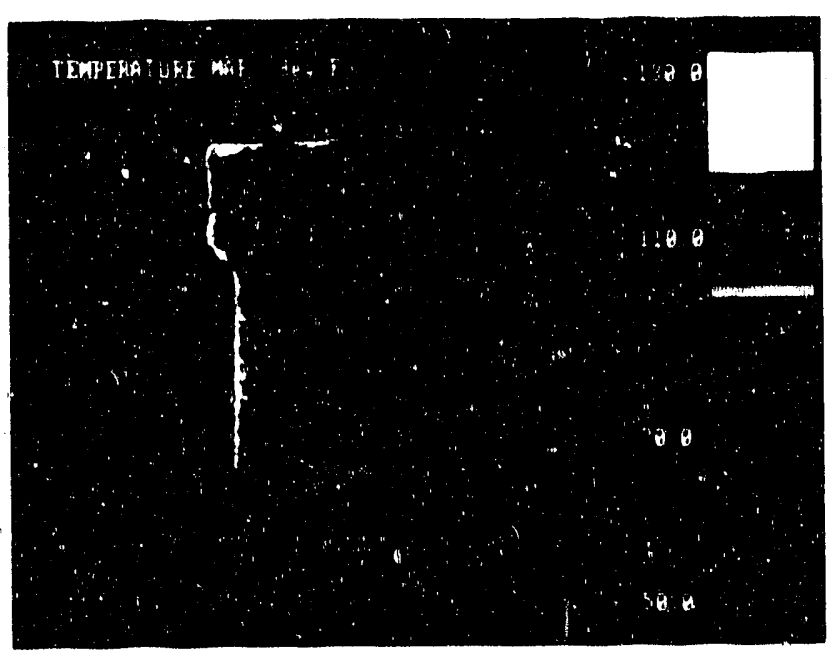

(c)

Fig. 17. Temperature distribution across a curved surface using a simple three-color map. Images $(a)$, (b), and (c), represent heating from cool to hot, respectively. 


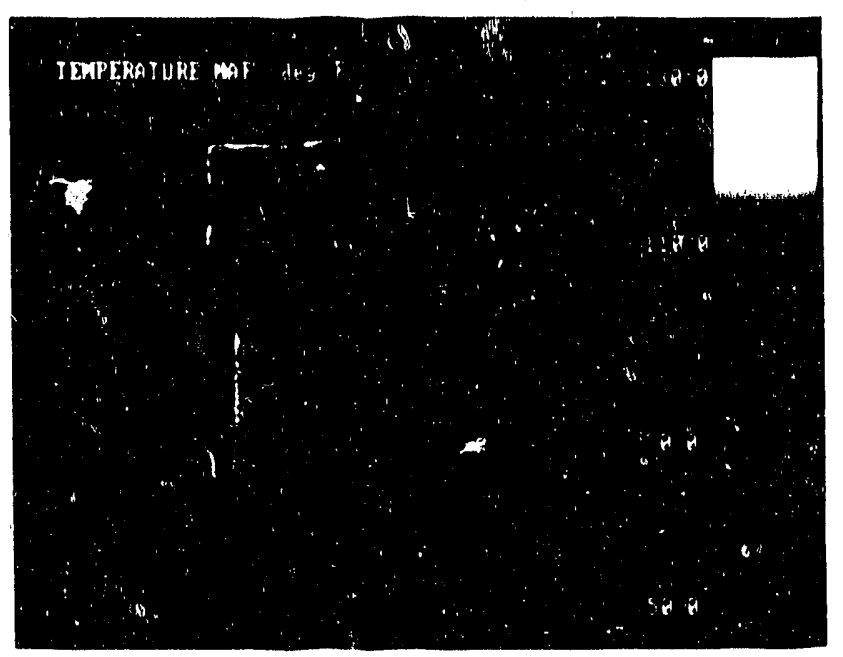

(a)

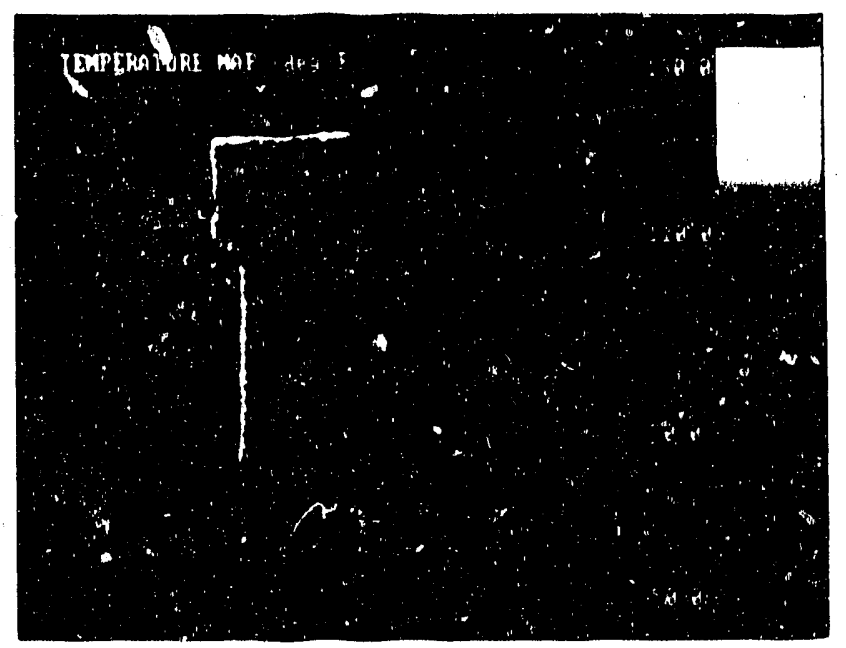

(b)

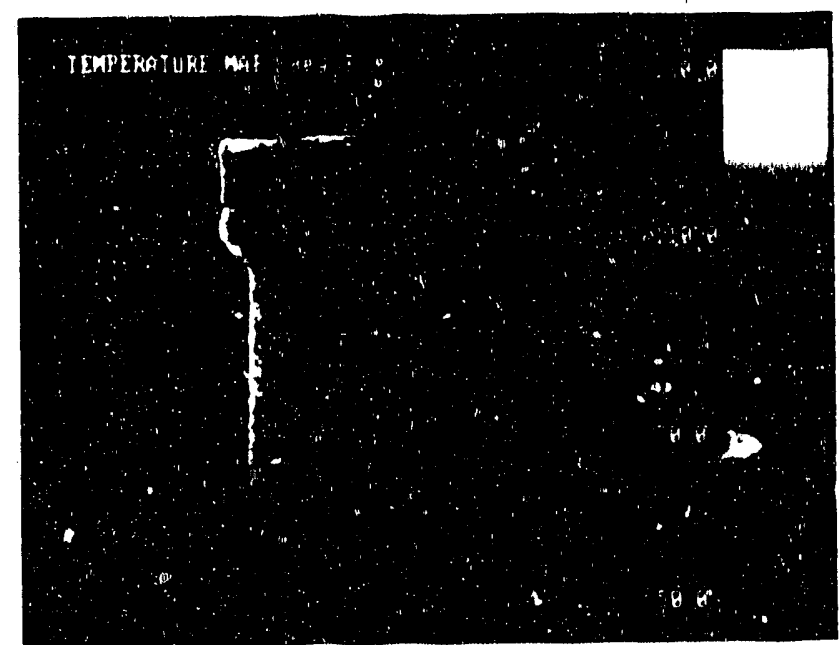

(c)

Fig. 18. Temperature distribution across a curved surface using a continuous color inap. Images $(a)$, (b), and (c), represent healing from cool to hot, respectively. 


$$
T(r)=218.0-666.7 r \pm \sigma_{T}\left({ }^{\circ} F\right)
$$

where the fit error has been determined to be $\sigma_{\mathrm{T}}= \pm 2.0^{\circ} \mathrm{F}$ and could be further reduced by increasing $\mathrm{I}_{\text {image }}$ or reducing $\sigma_{\text {image }}$. Therefore, the limitation of temperature resolution demonstrated by Figs. 17 and 18 is not inherent to the phosphor-ratio method but rather to the presence of image noise and low-intensity data-problems which will be overcome in the development of a dedicated system.

The thermophosphor-ratio technique represents a viable method for determination of 2-D surface temperature in unstable environments. The procedures described in this report are not system specific and should be considered when a dedicated imaging system is assembled to perform this task. The selection of a phosphor material can readily be tailored to meet the needs of both high- and low-temperature regimes, while a simple calibration function [such as that expressed by Eq. (18)] can be fit to the experiment of interest.

\section{MATERIAT S FOR HIGH TEMPERATURE MODELS}

The advantages of the present RTV-60 and similar castable formulations for fabricating models are the relative ease of molding the required shapes and the low cost of the material. The relatively low temperatures, however, at which these materials begin to lose structural integrity provide a serious disadvantage that must be compensated for in future highertemperature models. There is also a problem of cracking, in some instances, which can be a serious limitation. Three types of higher-temperature materials could be used to produce moderaiely priced models satisfactory for the future aerodynamic testing needs at AEDC and similar facilities. These include (1) machinable ceramics, (2) moldable ceramics and plastics, and (3) surface ceramic or compositc coatings on lower-temperature substructures. All three types have thermal conductivities low enough to produce a relatively stable temperature pattern from flow impact, and all three have higher temperature stability than present epoxybased structures. For ceramics, in particular, the range of temperatures at which they would be useful cun be extended greatly, because most ceramics will remain stable to $3500^{\circ} \mathrm{F}$ or higher.

\section{MACHINABLE CERAMICS}

At least two types of machinable ceramics are available. One type is a natural material called lavite, which is a type of soapstone that is quite soft and machinable in its natural state, but which converts to a hard ceramic when cured. Curing at $-1500^{\circ} \mathrm{F}$ for $-24 \mathrm{~h}$ has been used at ORNL. It has good structural integrity when properly processed. The final product does grow in dimension $\sim 4 \%$, which must be taken into account in the machining. There are also other materials that have been developed to be machinable. One typical example is the product called Macor. It is made of a ceramic powder mixed into a glass matrix. The combination becomes a machinable, hard ceramic that does not chip or crack easily. It will not withstand temperatures as high as most ceramics - namely, about $3000^{\circ} \mathrm{F}$ or higher - but is quite useful up to $2000^{\circ} \mathrm{F}$ or somewhat $\mathrm{n}_{\mathrm{s}}$ ore. 


\section{MOLDABLE CERAMICS}

This is a new area in high-temperature materials techrology, but it also is one of the oldest manufacturing methods in the world. Molded parts are made of ceramic powders suspended in liquid binders and then dried and fired in high-temperature kilns. The results are typically hollow and have smooth, hard finishes. By thickening the powder slurries and modifying the drying and firing procedures, thicker structures can be prepared.

Perhaps the most exciting modern version of this technology, however, is the gel casting technique. Ceramic powder is added to an organic monimor and poured into a mold where it polymerizes into a gel. The binder then is burned off by a firing process. The advantage of gel casting is that the prefired part has a rubbery texture, making it able to conform to complex mold detail and be able to be removed from the mold with no surface damage. As a finished material, it is stable up to about $3000^{\circ} \mathrm{F}$. At ORNL, an important contact for the gel method is M. Janney, P.O. Box 2008, Oak Ridge, Tennessee 37831. Gel casting should be given serious consideration for the new generation of models.

Another product is a ceramic molding material that can be formed at room temperature. One product, made by A. C. E. Corporation, is pourable and sets at room temperature. It has a density of $\sim 117 \mathrm{lb} / \mathrm{ft}^{3}$, a low thermal expansion, and will withstand temperatures up to $3000^{\circ} \mathrm{F}$. The commercial contact is A. C. E., Inc., 121-18 Du Pont Street, Plainview, New York 11803. Molding material of this type should also be given serious consideration for future AEDC needs.

Some plastics, such as thermoplastics, have higher breakdown temperatures than the present model materials in use at AEDC, while retaining the necessary heat-transfer characteristics. For example, a thermoplastic called PEEK (polyether ether ketone) melts at $-750^{\circ} \mathrm{F}$, making it useful for some model applications. Plastics of this sort can be used, too, as matrices for carbon, glass, or other fibers, to form composites that have very high strength structural characteristics. To mold or otherwise fabricate an accurate model from composite is, however, not a common or simple procedure. Other moldable epoxies, such as stycast, could also be used. Any of these plastics will only add a limited increase of temperature range for models, so it is recommended that ceramics be given priority consideration for new model materials. A good contact in this epoxy/plastics area is R. G. Rudness in the Applied Technology Division (ATD) at ORNL.

\section{COATINGS ON SUBSTRUCTURES}

This method is a hybrid approach to developing high-temperature models. A simple molded form, using stycast, the present RTV material, or something similar, would produce the basic shape of the model. On that form, then, a ceramic material can be added to form a high-temperature structure. Depending on the needs the outer coating can be thick or thin. It could also have advantages for tailoring the heat transfer properties near the surface. Ceramic cements, such as Saureisen, could perhaps be used, then smoothed with abrasive tools to form an appropriate surface. The coating could also be made by one of the moldable materials mentioned above, or applied by a plasma or flame stray technique. A likely approach, though, would be to use a binder for the ceramic powder and apply it with a simple 
airbrush system. The airbrush system is also an appropriate way to add the thermographic phosphor coat to any of the model configurations. If the phosphor is actually built in to the ceramic overcoat-for example, by using doped yttria as a thermographic phosphor-the surface becomes thermographic, even as it is being oblated away by the high-speed flows in an aerodynamic test.

Thermographic phosphor coatings were applied using binders and the airbrush method on test samples of model materials, as well as on numerous other ceramic samples. Although detailed quantitative evaluation is outside the scope of this survey, past experience and qualitative results indicate that this application method will be suitable for practically all anticipated models for AEDC use. In the expected follow-up work in this area, specific test models should be fabricated and evaluated in ATD laboratories and then in the wind tunnel environment at AEDC.

\section{CONCLUSIONS AND RECOMMENDATIONS}

The wavelength ratio method of measuring surface temperatures of aerodynamic models was demonstrated in measurements made for this project. In particular, it was shown that the appropriate phosphors could be selected for the temperature range up to $\sim 700^{\circ} \mathrm{F}$ or higher with emission-line ratios of sufficient sensitivity to measure temperature with $1 \%$ precision or better. Further, it was demonstrated that 2-D image-processing methods, using standard hardware, could be successfully applied to surface thermography of aerodynamic models for AEDC applications.

This study, though preliminary in nature, is supported by a large body of research and development in the area of phosphor thermography. Since 1983 more than $\$ 2.5 \mathrm{M}$ of funding has been invested in the technology. It is believed that the applicability to AEDC aerodynamic testing is especially important. With respect to the new initiatives on higher-Mach-number tests on high-temperature materials with different thermal and structural characteristics, modern phosphor technology, coupled with imaging processing techniques offers the best diagnostic resource for future surface temperature studies. It is strongly recommended that ATD personnel at ORNL collaborate with AEDC personnel on a development program to produce a 2-D thermography system for aerodynamic testing. In the new system, modern phosphor technology will be coupled with image-processing techniques employed with standard hardware. Such a system will not only offer high-quality and high-reliability measurements for the near term but can be upgraded in straightforward ways as future experimental demands dictate.

A suggested approach to lead into this development program is to perform a 2-D phosphor measurement on an existing test model as a parallel or add-on effort in a scheduled AEDC test. This feasibility measurement will provide a clear illustration of the advantages and capabilities of the technique and will provide relevant data to support requests for a fullscale development program. 


\section{REFERENCES}

1. K. A. Wickersheim and R. A. Lefeuer, "Luminescent Behavior of the Rare Earths in Yttrium Oxide and Related Hosts," J. Electrochem. Soc. 111, 45 (1964).

2. W. D. Turley et al., EG\&G Energy Measurements, private communication.

3. W. H. Atkinson et al., Design of a Scanning Pyrometer System for Hot Section Static Structures, AFWAL-TR-86-2116, April 1987.

4. B. W. Noel et al., Evaluating and Testing Thermographic Phosphors for TurbineEngine Temperature Measurements, AIAA-76-1761, AIAA/SAE/ASME/ASEE 23rd Joint Propulsion Conference, San Diego, California, June 29-July 2, 1987.

5. M. R. Cates et al., Applications of Pulsed-Laser Techniques and Thermographic Phosphors to Dynamic Thermometry of Rotating Surfaces, Martin Marietta Energy Systems, Inc., Oak Ridge Gaseous Diffusion Plant, 1984.

6. G. T. Gillies et al., Non-contact Thermometry via Laser Pumped, Thermographic Phosphors: Characterizations of Systematic Errors and Industrial Applications, K/ETAC-32, Martin Marietta Energy Systems, Inc., Oak Ridge Gaseous Diffusion Plant, October 1987.

7. K. W. Tobin et al., Remote High-Temperature Thermometry of Rotating Test Blades Using $\mathrm{YVO}_{4}:$ Eu and $\mathrm{Y}_{2} \mathrm{O}_{3}:$ Eu Thermographic Phosphors, Paper 88-3147, AIAA/SAE/ASME 24th Joint Propulsion Conference July 1988.

8. K. W. Tobin et al., Engine Testing of Thermographic Phosphors. Part 1: Pratt \& Whitney Fixed-Blade Test. Part 2: Virginia Polytechnic Institute Turbine-Blade Test., ORNL/ATD-31, Martin Marietta Energy Systems, Inc., Oak Ridge Natl. Lab., 1990.

9. W. D. Turley et al., The Design and Characterization of a Prototype Optical Heat-Flux Gauge, LA-11408-MS, Los Alamos Natl. Lab., Los Alamos, NM, 1989.

10. B. K. P. Horn, Robot Vision, The MIT Electrical Engineering and Computer Science Series, McGraw-Hill Book Company, New York, 1986.

11. W. H. Fonger and C. W. Struck, " $E u^{+3}{ }^{5} \mathrm{D}$ Resonance Quenching to the Charge Transfer States in $\mathrm{Y}_{2} \mathrm{O}_{2} \mathrm{~S}, \mathrm{La}_{2} \mathrm{O}_{2} \mathrm{~S}$, and LaOCl," J. Chem. Phys. 52(12), 6364, June 15, 1970.

12. M. Young, Optics and Lasers, Including Fibers and Optical Waveguides, 3rd ed., Springer Series in Optical Sciences, Vol. 5, Springer-Verlag, New York, 1986.

13. J. Mandel, The Statistical Analysis of Experimental Data, Dover Publications, Inc., New York, 1964. 

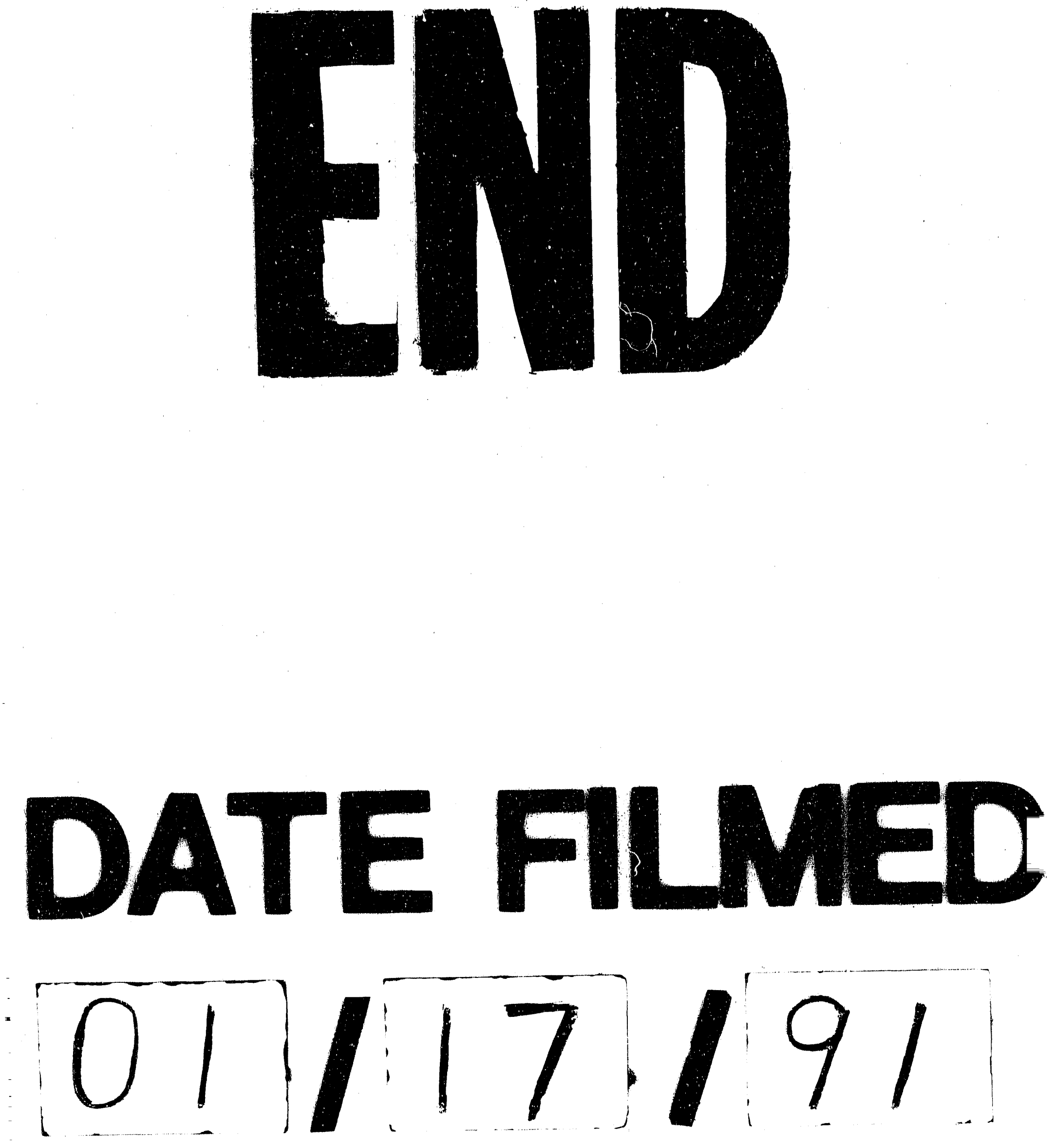


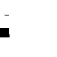

